\title{
9 Transcriptomics of the Fungal Pathogens, Focusing on Candida albicans
}

\author{
STEFFEN RupP ${ }^{1}$
}

\section{CONTENTS}

I. Introduction. .................

A. Prerequisite for Transcriptomics:

Genomic Sequences.............

II. Transcriptomics of Fungal Pathogens ....

A. Transcriptomics of Primary

Fungal Pathogens..............

B. Transcriptomics of Opportunistic

Fungal Pathogens..............

III. Transcriptomics of Candida albicans ....

A. Resistance Mechanisms

to Antimycotics ................

1. Response of C. albicans

to Antimycotics.............

2. Transcriptional Profiling of Clinical Isolates Resistant

to Antimycotics ..............

3. Experimental Induction of Resistance ...............

4. Antimycotics for Topical Applications.................

B. Stress Response ...............

1. General Stress Response in C. albicans .................

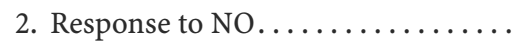

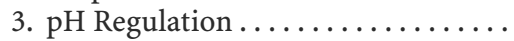

C. Polymorphism of C. albicans.........

1. Yeast to Hyphae Transition ........

2. The APSES Proteins Efg1 and Efh1 in C. albicans...........

3. cAMP Signalling ..............

4. Repression of Transcription as Key for Morphogenesis ........

5. Phenotypic Switching

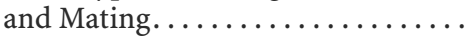

D. Host-Pathogen Interaction...$\ldots \ldots$

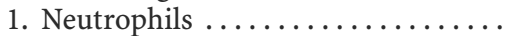

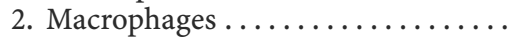

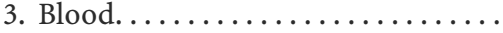

4. Epithelial Surfaces..............

E. Biofilm Formation ...............

IV. Conclusions ....................

References....................
187

188

193

\footnotetext{
${ }^{1}$ Fraunhofer IGB, Nobelstrasse 12, 70569 Stuttgart, Germany; e-mail: rupp@igb.fhg.de
}

\section{Introduction}

The past century brought the availability of vaccines and antibiotics, leading to a dramatic fall in mortalities caused by infectious diseases. This led to the assumption that infectious disease has been defeated by medicine. In 1969 the United States Surgeon General actually claimed that "we can close the book on infectious diseases". However, today we know that this assumption was naïve, not taking into account that evolution is a constant motor in adapting the existing organisms to changing environmental conditions, including the adaptation of pathogens to changes in the host. Today nearly $25 \%$ of the annual deaths world-wide are directly related to pathogens (Morens et al.2004). This can be attributed to the appearance of new diseases, like HIV, SARS or West Nile Virus, but also to an increase of resistance to antibiotics in pathogens thought to be defeated, like Mycobacterium tuberculosis or Staphylococcus and Enterococcus strains. In addition the progress in medical care results in a large proportion of immune-deficient patients and consequently in an increase in opportunistic infections. Especially fungi have gained an infamous reputation during recent decades as being highly detrimental to patients with haematologiconcologic diseases, neutropenia or after organ transplantation. A review of the current literature identified 1415 species as known to be pathogenic to humans, including 538 bacteria and 307 fungi (Cleaveland et al. 2001). The fungi are a large group of diverse eukaryotic organisms. Only about 74000 to 120000 of the estimated $1.5 \times 10^{6}$ existing species of fungi have been described. Of the approximately 300 fungal species that are known to cause human infections, the most commonly observed live threatening systemic infections are caused by opportunistic infections of Candida species or Aspergilli. Therefore the major scientific interest with regard to fungal pathomechanisms has focused on these organisms in the past decade. 
The early availability of the genome sequence of Candida albicans (the first assembly of the genome sequence was publicly available in 2000 , at http://www-sequence.stanford.edu/group/candida), the availability of molecular tools and the use of Saccharomyces cerevisiae as a model for many characteristics of $C$. albicans relevant for pathogenesis (including morphogenesis and signalling pathways involved in stress response) resulted in a major body of work concerning this opportunistic fungal pathogen (Berman and Sudbery 2002; Braun et al. 2005; Jones et al. 2004). Until 2004 C. albicans was actually the only fungal pathogen on which genome-wide transcriptomics using arrays had been published. The sequences of other pathogenic fungi or the tools required for genome-wide transcriptomics had not been available to the public until then. However, a major body of molecular work has been performed on other opportunistic fungal pathogens, including C. glabrata, C. parapsylosis, C. tropicalis, Cryptococcus neoformans and Aspergillus species, where Aspergillus fumigatus is leading the clinically relevant species, as well as on the genera of primary fungal pathogens, including Blastomyces, Coccidioides, Histoplasma and Paracoccidioides. Due to the advancement of Candida albicans transcriptomics this chapter mainly focuses on this organism and only briefly touches the current work on other fungal pathogens.

\section{A. Prerequisite for Transcriptomics: Genomic Sequences}

The availability of complete genomic sequences and new methods to use this knowledge was key for the development and use of genome-wide technologies, including array technologies. Within the past decade sequencing of entire genomes has been a major effort both in academic as well as in commercial research. The first sequenced eukaryotic genome was the genome of Sac. cerevisiae (the second completely sequenced genome at all) in 1996. Only five years later a first draft of the human genomic sequence was published (Lander et al. 2001; Venter et al. 2001). Now the genome sequences of significantly more than 1000 organisms, including all kingdoms and viral genomes as well as the genomes of almost all the major pathogenic microbes, can be found in various databases, e.g. at NCBI Entrez Genomes, in different stages of their emergence, e.g. as completed annotated sequences, sequences in assembly or progress (http://www.ncbi.nlm.nih.gov/entrez/query.fcgi?C $\mathrm{MD}=$ Details $\& \mathrm{DB}=$ genome). As a consequence, a new discipline has arisen, which has been named "pathogenomics." As the name implies, pathogenomics is the analysis at the genomic level of the processes involved in pathogenesis caused by the interaction of pathogenic microbes and their hosts (for a review, see Pompe et al. 2005).

A recent review by Galagan summarizes all the fungal genome sequencing projects that are publicly available at any of the stages, from nominated candidates to fully assembled and annotated genomes (Galagan et al. 2005). Galagan focuses on comparative genomics. Currently 85 fungal genome sequences are listed at the NCBI of which nine are referenced as completed and 44 are at the assembly stage (as of 4 August 2006; Table 9.1). A total of 16 links to publications of fungal genomic sequences are given, including annotations of the respective genome (http://www.ncbi.nlm.nih.gov/ genomes/leuks.cgi). Besides model organism like Sac. cerevisiae or Schizosaccharomyces pombe, this list contains several of the human pathogenic fungi, including C. albicans, C. glabrata, C. tropicalis, Cryptococcus neoformans var. neoformans, A. fumigatus, Histoplasma capsulatum and Coccidioides immitis among others (Dujon et al. 2004; Jones et al. 2004; Loftus et al. 2005; Nierman et al. 2005). The availability of the increasing wealth of fungal sequences is largely due to initiatives for fungal genomics applying a kingdom-wide approach like the Fungal Genome Initiative of the Broad Institute (http://www.broad.mit.edu/annotation/fungi/fgi/index.html) or the Genolevures consortium(http://cbi.labri.fr/Genolevures/).Both initiatives selected a well defined collection of fungi (rather than choosing individual fungi in isolation) that maximizes the overall value for comparative genomics, evolutionary studies, eukaryotic biology and medical studies.

Based on these complete genomic sequences, DNA-microarray technology has been widely used for expression profiling, to monitor changes of transcriptional activity of every known or annotated gene of the respective fungi in a single experiment. For Sac. cerevisiae the first genome-wide transcriptional analyses appeared shortly after completion of the genomic sequence (DeRisi et al. 1997; Hauser et al. 1998; Wodicka et al. 1997). This set the start for genome-wide analysis of an organism based on the knowledge of its genome. Thus Sac. 
Table 9.1. Status of fungal genome sequencing projects as of August 2006

\begin{tabular}{|c|c|c|c|c|c|c|}
\hline Organism name & $\begin{array}{l}\text { Organism } \\
\text { subgroup }\end{array}$ & Size $(\mathrm{Mb})$ & Status & Depth & $\begin{array}{l}\text { Sequence } \\
\text { release date } \\
\text { (month/day/ } \\
\text { year) }\end{array}$ & Center/Consortium \\
\hline $\begin{array}{l}\text { Ajellomyces capsu- } \\
\text { latus G186AR }\end{array}$ & Ascomycetes & 24.0 & In progress & $2 x$ & & $\begin{array}{l}\text { Washington } \\
\text { University (WashU) }\end{array}$ \\
\hline $\begin{array}{l}\text { Aje. capsulatus } \\
\text { G217B }\end{array}$ & Ascomycetes & 24.0 & In progress & $8 \times$ & & $\begin{array}{l}\text { Washington } \\
\text { University (WashU) }\end{array}$ \\
\hline $\begin{array}{l}\text { Aje. capsulatus } \\
\text { NAm1 NAm I }\end{array}$ & Ascomycetes & 28.0 & Assembly & $4 \times$ & $09 / 21 / 2005$ & Broad Institute \\
\hline $\begin{array}{l}\text { Aje. dermatitidis } \\
\text { ATCC } 26199\end{array}$ & Ascomycetes & 28.0 & In progress & $3 x$ & & $\begin{array}{l}\text { Washington } \\
\text { University (WashU) }\end{array}$ \\
\hline $\begin{array}{l}\text { Antonospora } \\
\text { locustae }\end{array}$ & Other Fungi & 2.9 & In progress & $3 x$ & & $\begin{array}{l}\text { Marine Biological } \\
\text { Laboratory }\end{array}$ \\
\hline $\begin{array}{l}\text { Ascosphaera apis } \\
\text { USDA-ARSEF } \\
7405\end{array}$ & Ascomycetes & 24.0 & Assembly & $4 \times$ & 07.06 .2006 & $\begin{array}{l}\text { Baylor College of } \\
\text { Medicine }\end{array}$ \\
\hline $\begin{array}{l}\text { Aspergillus clava- } \\
\text { tus NRRL } 1\end{array}$ & Ascomycetes & 35.0 & Assembly & $11.4 \times$ & 09.09.2005 & TIGR \\
\hline $\begin{array}{l}\text { Asp. flavus } \\
\quad \text { NRRL } 3357\end{array}$ & Ascomycetes & 36.0 & Assembly & $5 x$ & 08.01 .2005 & TIGR \\
\hline $\begin{array}{l}\text { Asp. fumigatus } \\
\text { Af } 293\end{array}$ & Ascomycetes & 30.0 & Assembly & $10 \times$ & 06.01 .2005 & $\begin{array}{l}\text { TIGR/Sanger } \\
\text { Institute }\end{array}$ \\
\hline $\begin{array}{l}\text { Asp. nidulans } \\
\text { FGSC A4 }\end{array}$ & Ascomycetes & 31.0 & Assembly & $13 x$ & 04.07 .2003 & Broad Institute \\
\hline Asp.parasiticus & Ascomycetes & & In progress & & & $\begin{array}{r}\text { University of } \\
\text { Oklahoma }\end{array}$ \\
\hline $\begin{array}{l}\text { Asp. terreus ATCC } \\
20542\end{array}$ & Ascomycetes & 35.0 & Assembly & & $01 / 22 / 2003$ & Microbia \\
\hline $\begin{array}{r}\text { Asp. terreus } \\
\text { NIH2624 }\end{array}$ & Ascomycetes & 35.0 & Assembly & $11.05 \times$ & $08 / 30 / 2005$ & Broad Institute \\
\hline $\begin{array}{l}\text { Batrachochytrium } \\
\text { dendrobatidis }\end{array}$ & Other Fungi & 20.0 & In progress & $10 x$ & & Broad Institute \\
\hline $\begin{array}{l}\text { Botryotinia fuck- } \\
\quad \text { eliana }\end{array}$ & Ascomycetes & 38.0 & In progress & $10 x$ & & $\begin{array}{l}\text { Genoscope/Bayer } \\
\text { CropScience }\end{array}$ \\
\hline $\begin{array}{l}\text { Bot. fuckeliana } \\
\quad \text { B05.10 }\end{array}$ & Ascomycetes & 38.0 & Assembly & $5.4 \times$ & $10 / 20 / 2005$ & $\begin{array}{l}\text { Syngenta Biotech., } \\
\text { Inc./Broad Institute }\end{array}$ \\
\hline $\begin{array}{l}\text { Candida albicans } \\
\quad 1161\end{array}$ & Ascomycetes & & In progress & & & $\begin{array}{l}\text { Welcome Trust Sanger } \\
\text { Institute }\end{array}$ \\
\hline $\begin{array}{l}\text { Can. albicans } \\
\quad \text { SC5314 }\end{array}$ & Ascomycetes & 16.0 & Assembly & & $02 / 24 / 2001$ & Stanford University \\
\hline $\begin{array}{l}\text { Can. albicans } \\
\quad \text { WO-1 }\end{array}$ & Ascomycetes & 14.0 & Assembly & $10 \times$ & $03 / 28 / 2006$ & Broad Institute \\
\hline $\begin{array}{c}\text { Can. glabrata } \\
\text { CBS } 138\end{array}$ & Ascomycetes & 12.2 & Complete & $8 \times$ & 07.02 .2004 & $\begin{array}{l}\text { Genolevures } \\
\text { Consortium }\end{array}$ \\
\hline $\begin{array}{l}\text { Can. tropicalis } \\
\quad \text { CBS } 94\end{array}$ & Ascomycetes & 15.0 & In progress & $0.2 \times$ & & $\begin{array}{l}\text { Genolevures } \\
\text { Consortium }\end{array}$ \\
\hline $\begin{array}{c}\text { Can. tropicalis } \\
\text { MYA-3404 }\end{array}$ & Ascomycetes & 15.0 & Assembly & $10 x$ & 03/16/2005 & Broad Institute \\
\hline $\begin{array}{l}\text { Chaetomium } \\
\text { globosum CBS } \\
148.51\end{array}$ & Ascomycetes & 36.0 & Assembly & $7 \times$ & 03/14/2005 & Broad Institute \\
\hline $\begin{array}{l}\text { Clavispora } \\
\quad \text { lusitaniae } \\
\text { ATCC } 42720\end{array}$ & Ascomycetes & 16.0 & Assembly & $9 x$ & $03 / 16 / 2005$ & Broad Institute \\
\hline $\begin{array}{l}\text { Coccidioides } \\
\quad \text { immitis H538.4 }\end{array}$ & Ascomycetes & 29.0 & In progress & $3 x$ & & Broad Institute \\
\hline Coc. immitis RS & Ascomycetes & 28.7 & Assembly & $10 \times$ & 10.04 .2004 & Broad Institute \\
\hline
\end{tabular}


Table 9.1. (continued)

\begin{tabular}{|c|c|c|c|c|c|c|}
\hline Organism name & $\begin{array}{l}\text { Organism } \\
\text { subgroup }\end{array}$ & Size $(\mathrm{Mb})$ & Status & Depth & $\begin{array}{l}\text { Sequence } \\
\text { release date } \\
\text { (month/day/ } \\
\text { year) }\end{array}$ & Center/Consortium \\
\hline $\begin{array}{l}\text { Coc. posadasii } \\
\quad \text { C735 }\end{array}$ & Ascomycetes & 29.0 & In progress & & & TIGR \\
\hline $\begin{array}{c}\text { Coprinopsis cinerea } \\
\text { okayama7\#130 }\end{array}$ & Basidiomycetes & 37.5 & Assembly & $10 x$ & 07/30/2003 & Broad Institute \\
\hline $\begin{array}{l}\text { Cryptococcus neo- } \\
\quad \text { formans R265 }\end{array}$ & Basidiomycetes & 20.0 & Assembly & $6 x$ & 03/17/2005 & Broad Institute \\
\hline $\begin{array}{l}\text { Cry. neoformans } \\
\text { WM276 }\end{array}$ & Basidiomycetes & 18.3 & In progress & $6 x$ & & $\begin{array}{l}\text { Genome Sciences Cen- } \\
\text { tre/Univ. of British } \\
\text { Columbia }\end{array}$ \\
\hline $\begin{array}{l}\text { Cry. neoformans } \\
\text { var. grubii H99 }\end{array}$ & Basidiomycetes & 20.0 & Assembly & $11 \times$ & $06 / 24 / 2003$ & $\begin{array}{l}\text { Broad Institute/Duke } \\
\text { University }\end{array}$ \\
\hline $\begin{array}{l}\text { Cry. neoformans } \\
\text { var. neoformans } \\
\text { B-3501A }\end{array}$ & Basidiomycetes & 18.5 & Assembly & & 07/13/2004 & Stanford Univ. \\
\hline $\begin{array}{l}\text { Cry. neoformans } \\
\text { var. neoformans } \\
\text { JEC21 }\end{array}$ & Basidiomycetes & 19.1 & Complete & $12.5 \times$ & 01.07 .2005 & $\begin{array}{l}\text { TIGR/Stanford Uni- } \\
\text { versity }\end{array}$ \\
\hline $\begin{array}{l}\text { Debaryomyces } \\
\quad \text { hansenii CBS767 }\end{array}$ & Ascomycetes & 12.2 & Complete & $9.7 \times$ & 07.02 .2004 & $\begin{array}{l}\text { Genolevures Consor- } \\
\text { tium }\end{array}$ \\
\hline $\begin{array}{l}\text { Encephalitozoon } \\
\quad \text { cuniculi GB-M1 }\end{array}$ & Other Fungi & 2.5 & Complete & & $11 / 24 / 2001$ & $\begin{array}{l}\text { Genoscope|Universite } \\
\text { Blaise Pascal }\end{array}$ \\
\hline $\begin{array}{l}\text { Eremothecium } \\
\text { gossypii ATCC } \\
10895\end{array}$ & Ascomycetes & 8.74 & Complete & & 03.06 .2004 & $\begin{array}{l}\text { Zool. Institut der Univ. } \\
\text { Basel, Switzerland }\end{array}$ \\
\hline $\begin{array}{l}\text { Gibberella monili- } \\
\text { formis } 7600\end{array}$ & Ascomycetes & 46.0 & Assembly & $4.2 \times$ & $10 / 20 / 2005$ & $\begin{array}{l}\text { Syngenta Biotech., } \\
\text { Inc./Broad Institute }\end{array}$ \\
\hline G. zeae PH-1 & Ascomycetes & 40.0 & Assembly & $10 x$ & 05.09 .2003 & $\begin{array}{l}\text { International } \\
\text { Gibberella zeae } \\
\text { Genomics } \\
\text { Consortium/Broad } \\
\text { Institute }\end{array}$ \\
\hline $\begin{array}{l}\text { Kazachstania } \\
\quad \text { exigua CBS } 379\end{array}$ & Ascomycetes & 18.0 & In progress & $0.2 \times$ & & $\begin{array}{l}\text { Genolevures } \\
\text { Consortium }\end{array}$ \\
\hline $\begin{array}{l}\text { Kluyveromyces } \\
\quad \text { lactis } N R R L \\
\quad Y-1140\end{array}$ & Ascomycetes & 10.7 & Complete & $11.4 \times$ & 07.02 .2004 & $\begin{array}{l}\text { Genolevures } \\
\text { Consortium }\end{array}$ \\
\hline $\begin{array}{l}\text { Klu. marxianus } \\
\text { CBS } 712\end{array}$ & Ascomycetes & 14.0 & In progress & $0.2 \times$ & & $\begin{array}{l}\text { Genolevures } \\
\text { Consortium }\end{array}$ \\
\hline $\begin{array}{l}\text { Klu. thermotoler- } \\
\text { ans CBS } 6340\end{array}$ & Ascomycetes & 10.6 & In progress & $0.2 \times$ & & $\begin{array}{l}\text { Genolevures } \\
\text { Consortium }\end{array}$ \\
\hline $\begin{array}{l}\text { Klu. waltii NCYC } \\
\quad 2644\end{array}$ & Ascomycetes & 10.9 & Assembly & $8 \times$ & 03.09 .2004 & Broad Institute \\
\hline $\begin{array}{l}\text { Lodderomyces } \\
\quad \text { elongisporus } \\
\quad \text { NRLL YB-4239 }\end{array}$ & Ascomycetes & 16.0 & In progress & $8 \times$ & & Broad Institute \\
\hline $\begin{array}{l}\text { Magnaporthe } \\
\text { grisea } 70-15\end{array}$ & Ascomycetes & 40.0 & Assembly & $7 x$ & $10 / 31 / 2003$ & $\begin{array}{l}\text { International Rice } \\
\text { Blast Genome } \\
\text { Consortium/Broad } \\
\text { Institute/Fungal } \\
\text { Genomics Lab., } \\
\text { North Carolina } \\
\text { State Univ. }\end{array}$ \\
\hline M. grisea $70-15$ & Ascomycetes & 40.0 & Assembly & & $01 / 30 / 2006$ & $\begin{array}{l}\text { North Carolina State } \\
\text { University (NCSU) }\end{array}$ \\
\hline
\end{tabular}


Table 9.1. (continued)

\begin{tabular}{|c|c|c|c|c|c|c|}
\hline Organism name & $\begin{array}{l}\text { Organism } \\
\text { subgroup }\end{array}$ & Size $(\mathrm{Mb})$ & Status & Depth & $\begin{array}{l}\text { Sequence } \\
\text { release date } \\
\text { (month/day/ } \\
\text { year) }\end{array}$ & Center/Consortium \\
\hline $\begin{array}{l}\text { Nectria haemato- } \\
\text { cocca MPVI }\end{array}$ & Ascomycetes & 40.0 & In progress & & & $\begin{array}{l}\text { DOE Joint Genome } \\
\text { Institute }\end{array}$ \\
\hline $\begin{array}{l}\text { Neosartorya } \\
\quad \text { fischeri NRRL } \\
\quad 181\end{array}$ & Ascomycetes & 35.0 & Assembly & & 09.09.2005 & TIGR \\
\hline $\begin{array}{l}\text { Neurospora crassa } \\
\text { OR74A }\end{array}$ & Ascomycetes & 43.0 & Assembly & $10 \times$ & $04 / 25 / 2003$ & Broad Institute \\
\hline $\begin{array}{l}\text { Phaeosphaeria } \\
\text { nodorum SN15 }\end{array}$ & Ascomycetes & & Assembly & & 04.04 .2005 & Broad Institute \\
\hline $\begin{array}{l}\text { Phakopsora meibo- } \\
\text { miae }\end{array}$ & Basidiomycetes & & In progress & $8 \times$ & & $\begin{array}{l}\text { DOE Joint Genome } \\
\text { Institute }\end{array}$ \\
\hline Phk. pachyrhizi & Basidiomycetes & 50.0 & In progress & $8 \times$ & & $\begin{array}{l}\text { DOE Joint Genome } \\
\text { Institute }\end{array}$ \\
\hline $\begin{array}{l}\text { Phanerochaete } \\
\text { chrysosporium } \\
\text { RP-78 }\end{array}$ & Basidiomycetes & 30.0 & Assembly & & 05.04 .2004 & $\begin{array}{l}\text { DOE Joint Genome } \\
\text { Institute }\end{array}$ \\
\hline $\begin{array}{l}\text { Pichia angusta } \\
\quad \text { CBS } 4732\end{array}$ & Ascomycetes & & In progress & $0.5 \times$ & & $\begin{array}{l}\text { Genolevures } \\
\text { Consortium }\end{array}$ \\
\hline Pic. angusta RB11 & Ascomycetes & 9.5 & In progress & $8 \times$ & & Qiagen \\
\hline $\begin{array}{l}\text { Pic. farinosa CBS } \\
\quad 7064\end{array}$ & Ascomycetes & 13.9 & In progress & $0.4 \times$ & & $\begin{array}{l}\text { Genolevures } \\
\text { Consortium }\end{array}$ \\
\hline $\begin{array}{l}\text { Pic. guilliermondii } \\
\text { ATCC } 6260\end{array}$ & Ascomycetes & 12.0 & Assembly & $12 x$ & $03 / 17 / 2005$ & Broad Institute \\
\hline $\begin{array}{l}\text { Pic. stipitis CBS } \\
\quad 6054\end{array}$ & Ascomycetes & 15.4 & In progress & & & $\begin{array}{l}\text { DOE Joint Genome } \\
\text { Inst./Stanford Univ. }\end{array}$ \\
\hline $\begin{array}{l}\text { Pneumocystis } \\
\text { carinii }\end{array}$ & Ascomycetes & 8.0 & In progress & & & $\begin{array}{l}\text { University of Cincin- } \\
\text { nati }\end{array}$ \\
\hline $\begin{array}{l}\text { Podospora anse- } \\
\text { rina }\end{array}$ & Ascomycetes & 34.0 & In progress & $7 \times$ & & Broad Institute \\
\hline $\begin{array}{l}\text { Pod. anserina S } \\
\qquad \text { mat }^{+}\end{array}$ & Ascomycetes & 34.0 & In progress & $10 \times$ & & $\begin{array}{l}\text { Genoscope/CGM at } \\
\text { the CNRS/Orsay } \\
\text { Univ./Univ. } \\
\text { Bordeaux II/ } \\
\text { Wageningen Univ. }\end{array}$ \\
\hline $\begin{array}{l}\text { Rhizopus oryzae } \\
\text { RA } 99-880\end{array}$ & Other Fungi & 40.0 & Assembly & $10 \times$ & $03 / 17 / 2005$ & Broad Institute \\
\hline $\begin{array}{l}\text { Saccharomyces } \\
\text { bayanus 623-6C }\end{array}$ & Ascomycetes & 11.5 & Assembly & $2.9 \times$ & $05 / 31 / 2003$ & $\begin{array}{l}\text { Washington } \\
\text { University (WashU) }\end{array}$ \\
\hline $\begin{array}{l}\text { Sac. bayanus } \\
\text { MCYC } 623\end{array}$ & Ascomycetes & 11.5 & Assembly & $6.4 \times$ & $05 / 16 / 2003$ & Broad Institute \\
\hline $\begin{array}{l}\text { Sac. castellii NRRL } \\
\quad Y-12630\end{array}$ & Ascomycetes & & Assembly & $3.9 \times$ & $05 / 31 / 2003$ & $\begin{array}{l}\text { Washington } \\
\text { University (WashU) }\end{array}$ \\
\hline $\begin{array}{l}\text { Sac. cerevisiae } \\
\quad \text { S288c }\end{array}$ & Ascomycetes & 12.1 & Complete & & $10 / 25 / 1996$ & $\begin{array}{l}\text { Sanger Institute/Euro- } \\
\text { pean Yeast Genome } \\
\text { Sequencing } \\
\text { Network (EYGSN)/ } \\
\text { McGill Univ./Stan- } \\
\text { ford Univ./Tsukuba } \\
\text { Life Science Center/ } \\
\text { Washington Univ. } \\
\text { (WashU) }\end{array}$ \\
\hline $\begin{array}{l}\text { Sac. cerevisiae } \\
\quad \text { RM11-1a }\end{array}$ & Ascomycetes & 12.0 & Assembly & $10 x$ & $03 / 16 / 2005$ & Broad Institute \\
\hline $\begin{array}{l}\text { Sac. cerevisiae } \\
\text { YJM789 }\end{array}$ & Ascomycetes & 16.0 & Assembly & $10 \times$ & 01.06 .2005 & Stanford University \\
\hline
\end{tabular}


Table 9.1. (continued)

\begin{tabular}{|c|c|c|c|c|c|c|}
\hline Organism name & $\begin{array}{l}\text { Organism } \\
\text { subgroup }\end{array}$ & Size $(\mathrm{Mb})$ & Status & Depth & $\begin{array}{l}\text { Sequence } \\
\text { release date } \\
\text { (month/day/ } \\
\text { year) }\end{array}$ & Center/Consortium \\
\hline $\begin{array}{l}\text { Sac. kluyveri NRRL } \\
\text { Y-12651 }\end{array}$ & Ascomycetes & 12.6 & Assembly & $3.6 \times$ & $05 / 31 / 2003$ & $\begin{array}{l}\text { Washington } \\
\quad \text { University (WashU) }\end{array}$ \\
\hline $\begin{array}{l}\text { Sac. kluyveri NRRL } \\
Y-12651\end{array}$ & Ascomycetes & & In progress & $0.2 \times$ & & $\begin{array}{l}\text { Genolevures Consor- } \\
\text { tium }\end{array}$ \\
\hline $\begin{array}{l}\text { Sac. kudriavzevii } \\
\text { IFO } 1802\end{array}$ & Ascomycetes & & Assembly & $3.4 \times$ & $05 / 31 / 2003$ & $\begin{array}{l}\text { Washington } \\
\quad \text { University (WashU) }\end{array}$ \\
\hline $\begin{array}{l}\text { Sac. mikatae IFO } \\
\quad 1815\end{array}$ & Ascomycetes & 12.1 & Assembly & $5.9 \times$ & $05 / 16 / 2003$ & Broad Institute \\
\hline $\begin{array}{l}\text { Sac. mikatae IFO } \\
\quad 1815\end{array}$ & Ascomycetes & 12.1 & Assembly & $2.8 \times$ & $05 / 31 / 2003$ & $\begin{array}{l}\text { Washington } \\
\quad \text { University (WashU) }\end{array}$ \\
\hline $\begin{array}{l}\text { Sac. paradoxus } \\
\quad \text { NRRL Y-17217 }\end{array}$ & Ascomycetes & 11.8 & Assembly & $7.7 \times$ & $05 / 16 / 2003$ & Broad Institute \\
\hline $\begin{array}{l}\text { Sac. servazzii CBS } \\
\quad 4311\end{array}$ & Ascomycetes & 12.3 & In progress & $0.2 \times$ & & $\begin{array}{l}\text { Genolevures } \\
\text { Consortium }\end{array}$ \\
\hline $\begin{array}{l}\text { Sac. uvarum CLIB } \\
\quad 533\end{array}$ & Ascomycetes & & In progress & $0.4 \times$ & & $\begin{array}{l}\text { Genolevures } \\
\text { Consortium }\end{array}$ \\
\hline $\begin{array}{l}\text { Schizosaccharomy- } \\
\text { ces japonicus }\end{array}$ & Ascomycetes & 14.0 & In progress & $7 x$ & & Broad Institute \\
\hline Sch.octosporus & Ascomycetes & 14.0 & In progress & $7 x$ & & Broad Institute \\
\hline Sch. pombe $972 h^{-}$ & Ascomycetes & 12.5 & Complete & $8 \times$ & $02 / 21 / 2002$ & $\begin{array}{l}\text { Sch. pombe European } \\
\text { Sequencing } \\
\text { Consortium } \\
\text { (EUPOM)/Sanger } \\
\text { Institute/Cold } \\
\text { Spring Harbor Lab }\end{array}$ \\
\hline $\begin{array}{l}\text { Sclerotinia sclero- } \\
\quad \text { tiorum } 1980\end{array}$ & Ascomycetes & 38.0 & Assembly & $8 \times$ & $09 / 20 / 2005$ & Broad Institute \\
\hline $\begin{array}{l}\text { Trichoderma reesei } \\
\text { QM9414 }\end{array}$ & Ascomycetes & 33.0 & Assembly & & 08.04.2005 & $\begin{array}{l}\text { DOE Joint Genome } \\
\text { Institute/Los } \\
\text { Alamos National } \\
\text { Laboratory }\end{array}$ \\
\hline $\begin{array}{l}\text { Uncinocarpus } \\
\text { reesii } 1704\end{array}$ & Ascomycetes & 30.0 & Assembly & $5 \times$ & $09 / 13 / 2005$ & Broad Institute \\
\hline $\begin{array}{l}\text { Ustilago maydis } \\
\quad 521\end{array}$ & Basidiomycetes & 20.0 & Assembly & $10 x$ & $07 / 29 / 2003$ & Broad Institute \\
\hline $\begin{array}{l}\text { Yarrowia lipolytica } \\
\quad \text { CLIB122 }\end{array}$ & Ascomycetes & 20.5 & Complete & $10 \times$ & 07.02 .2004 & $\begin{array}{l}\text { Genolevures } \\
\text { Consortium }\end{array}$ \\
\hline $\begin{array}{c}\text { Zygosaccharomyces } \\
\text { rouxii CBS } 732\end{array}$ & Ascomycetes & 12.8 & In progress & $0.4 \times$ & & $\begin{array}{l}\text { Genolevures } \\
\text { Consortium }\end{array}$ \\
\hline
\end{tabular}

cerevisiae was also key in developing both the biochemical and bioinformatic methods necessary for transcriptional profiling. Today thousands of transcription profiles have been generated from Sac. cerevisiae, which also can be of use for comparison to the biology of other fungi. At the Saccharomyces Genome Database (SGD, http://www. yeastgenome.org/), links to publicly available data sets have been set and many results thereof were integrated into the functional descriptions of genes (see SGD at http://www.yeastgenome.org/).
This amount of data shows that, besides the knowledge of the genome, ways to generate and analyse the data are a prerequisite for transcriptomics. Microarray fabrication and data analysis, however, are beyond the scope of this chapter and cannot be reviewed. For recent reviews, see Barbulovic-Nad et al. (2006) and Eisenstein (2006).

Transcriptomics can be used in several ways. The most straightforward way to use transcriptomics is to use it as a screening tool to study gene function or to identify individual genes required 
for adaptation to certain environmental conditions. This strategy mimics conventional mutational or promoter activation screens. Especially for pathogenic fungi with cryptic or absent sexual cycles - excluding the use of classic genetics - this technology greatly facilitates research. DNA-microarrays have the advantage that the mRNA levels of all genes represented on the array can be monitored in a single experiment avoiding tedious screening procedures which may be developed using conventional methods if possible at all. However, genes which have not been included in the arrays, e.g. due to exclusion from annotation because of size (usually the limit is at $100 \mathrm{bp}$ ), sequencing and annotation problems or other reasons, are not included in the analysis. A more comprehensive approach is the analysis of large sets of transcriptome data in order to create a picture of interconnected networks of signalling pathways. This can take account of the fact that signalling pathways in general are not operating in an isolated fashion, but rather form an entangled web of numerous possible signalling avenues and feedback loops (Carter et al. 2006; Ihmels et al. 2005).

There are also pitfalls one should keep in mind if working on a genome-wide level. For many of the genes in a genome defined by an open reading frame and annotated by homology to a gene from another organism, still no experimental evidence has been generated for its function, localisation or other parameters. Although the predictive models for gene/protein function are getting better and better, they are based on present knowledge. This might lead to incorrect conclusions based on incorrect assignment of functionalities. Furthermore, completely new functionalities may not be recognized in transcriptional profiling experiments based on the predictions included in the gene annotations. In addition regulatory mechanisms which do not require changes in mRNA levels, e.g. activating of signalling molecules by post-translational modifications, can not be detected using transcriptomics. Although transcriptional profiling is an excellent tool for unravelling complex interaction of cellular pathways, it should also be seen as a tool with certain limitations.

Nevertheless transcriptomics have been used to create a comprehensive picture of changes in gene expression of pathogenic fungi during host-pathogen interaction, stress response or other environmental challenges which ultimately will contribute to the better understanding of the mechanisms of infection and thus foster the development of new diagnostics, therapeutics and vaccines.

\section{Transcriptomics of Fungal Pathogens}

\section{A. Transcriptomics of Primary Fungal Pathogens}

Primary fungal pathogens are able to cause disease in individuals who have no immune deficiencies and are in good health. Dermatophytes are the most important group causing primary infections in humans, including athletes foot, tinea and other skin infections. Responsible for these infections are dermatophytes of the genera Trichophyton, Microsporum and Epidermophyton. Although these are probably the most common fungal infections worldwide, research on dermatophytes is underrepresented. Only one publicly available genome project for dermatophytes (T. rubum) is currently at the planning stage (http://www.broad.mit.edu/ annotation/fungi/fgi/nominated.html). Therefore no genome-wide transcriptional profiling experiments have been published to date.

Another group of primary fungal pathogens has been investigated in more detail. These encompass genera of dimorphic fungi including Blastomyces, Coccidioides, Histoplasma and Paracoccidioides. These fungi cause endemic mycoses in subtropical or tropical areas of the Americas or Africa. Sequencing projects for Coccoides imitis strains and Histoplasma capsulatum strains are well advanced (see Table 9.1). For H. capsulatum transcriptional studies using a shotgun array covering approximately one-third of the genome have been published already (Gebhart et al.2006; Hwang et al. 2003b). For C. imitis a partial array containing 1000 putative ORFs has just been employed (Johannesson et al.2006). Blastomyces dermatitidis and Paracoccidioides brasiliensis are on the list of nominated candidates for sequencing (http://www. broad.mit.edu/annotation/fungi/fgi/nominated. html). A significant body of work based on an ESTbased transcriptomic approach has been reported recently for P. brasiliensis (Andrade et al.2005).

\section{B. Transcriptomics of Opportunistic Fungal Pathogens}

Opportunistic fungal pathogens normally are not able to infect immunocompetent individuals. Some 
of them, e.g. Candida species like C. albicans are even part of the normal microflora of a large part of the population. Other fungi like A. fumigatus are normally saprophytic and Cryptococcus neoformans is associated with birds. These fungi may cause mycoses of various grades, including a high rate of fatal cases, in immunocompromised hosts like HIV, cancer and diabetes patients among others. For several of the opportunistic fungal pathogens the genomes have been completed, including sufficient annotation to enable the design of genomewide arrays for transcriptional profiling.

Currently, genome-wide transcriptional profiling experiments using arrays based on the genomic sequence of the organism have been published from four species of opportunistic fungi, Candida albicans, C. glabrata (Vermitsky et al. 2006), Cryptococcus neoformans (Cramer et al. 2006; Kraus et al.2004) and A. fumigatus (da Silva Ferreira et al. 2006; Nierman et al. 2005). By far the largest body of data has been created from Candida albicans. The Candida Genome database (Arnaud et al.2005; Costanzo et al.2006) lists 81 hits for genome-wide analysis publications (August 2006; http://www. candidagenome.org/cache/genome-wide-analysis. html) of which 66 are using transcriptome analysis. For the other organisms in total less than ten are found in PubMed (as of August 2006). Therefore, this review focuses on the transcriptomics of C. albicans.

\section{Transcriptomics of Candida albicans}

C. albicans is mostly found as a commensal organism which colonizes the gastrointestinal/urogenital tract in a large part of the population without causing any symptoms. However, C. albicans is able to switch between a commensal and a pathogen. This is in contrast to other opportunistic fungal pathogens like Aspergilli which are in general not part of the human microbial flora. Thus C. albicans has not only developed mechanisms to colonize, infect and invade into the host but must have developed mechanisms to persist in the host in large numbers without causing any damage. This switch between commensal and pathogen is central to C. albicans and has resulted in new definitions of pathogens (Casadevall and Pirofski 2003). Currently, no appropriate model system for commensalisms of fungi exists which restricts the work performed to study pathogenesis to more or less artificial model systems. Therefore, the symptom-free interplay between the host and a commensal fungus, which often is a prerequisite for infection, so far cannot been studied. The majority of the studies undertaken to date have been focusing on fundamental mechanisms generally thought to be required for pathogenesis, e.g. stress response, response to antimycotics, switching between different morphologies (yeast-to-hyphae transition) or the function of specific virulence genes by comparing mutant and wild-type or revertant strains in vitro. Furthermore, simple model systems mimicking host-pathogen interaction, e.g. C. albicans encountering the host defense, like macrophages or neutrophils or adhering and penetrating into tissue using different reconstituted tissue models derived from cell lines or primary cells, have been used to shed light into early stages of candidiasis. Also first attempts to directly investigate gene expression profiles of C. albicans isolated from patients have been reported.

For the C. albicans genome, several sequencing projects have been carried out, mostly commercially driven. A publicly available sequence of the genome was completed and assembled in 2000 by the Stanford Technology Centre (http://wwwsequence.stanford.edu/group/candida). However, due to the diploid character of the organism, even a ten-fold coverage of the genomic sequence could only be assembled in more than 1200 contigs, indicating significant ambiguities (assembly 4). The following assemblies were significantly improved. For the recent assembly 19, published in May 2002, the ploidy of the organism was taken into account and a diploid genome of $C$. albicans was assembled (266 contigs over eight chromosomes with a total of $14.88 \mathrm{Mb}$ of sequence). Assembly 20 has been released recently; however, in this case two different strain backgrounds have been inappropriately mixed to fill-in sequence gaps, resulting in small sequence stretches which might be inaccuarate (Arnaud et al.2007; Nantel 2006). Nevertheless, even with the early preliminary assembled sequences and many uncertainties in gene annotation, several comprehensive databases were initiated, describing predicted genes with respect to homologies to other organisms, especially Sac. cerevisiae (e.g. http:// genolist.pasteur.fr/CandidaDB/, http://wwwsequence. stanford.edu/group/candida or http://alces.med.umn. edu:80/Candida.html). While early on over 9000 ORFs were found in an automated ORF prediction 
procedure at the Stanford Technology Centre, between 6000 and 7200 ORFs were annotated in non-redundant gene sets in databases of different groups. These efforts resulted in several recent publications of the diploid sequence of C. albicans, its annotated ORFs and functional assignments (Braun et al. 2005; Costanzo et al. 2006; d'Enfert et al. 2005; Jones et al. 2004).

The publicly available sequence of the C. albicans genome by the Stanford Technology Centre was the basis for most of the transcriptome studies published to date. Early gene expression data, performed on DNA-arrays comprising subsets of about 300 up to 2000 genes of the genome as well as arrays containing groups of functionally related genes, e.g. like genes encoding for cell wall proteins, have been published by several groups (Bensen et al. 2002; Braun et al. 2001; Lane et al. 2001; Lotz et al. 2004; Murad et al. 2001; Sohn et al. 2003). The first microarray data predicting to cover almost the complete genome, however, derived from a commercial source of about 6600 cDNA library sequences, investigating $C$. albicans response to drug treatment (De Backer et al. 2001). Since then several groups have been developing genomewide arrays based on the public available sequence. Arrays used for the studies described here include arrays generated by Incyte Genomics (De Backer et al.2001), the high-density oligonucleotide GeneChip manufactured by Affymetrix (Santa Clara, Calif.; Lan et al. 2002), arrays based on spotted PCR products by the Biotechnology Research Institute (NRC, Montreal, Canada; http://www.irb-bri.cnrc.gc.ca/ microarraylab/; Nantel et al. 2002), by Eurogentec SA (Ivoz-Ramet, Belgium) in collaboration with the European Galar Fungail Consortium (www.pasteur.fr/ recherche/unites/Galar_Fungail/; Fradin et al.2003) and by Fraunhofer-IGB (Stuttgart, Germany; Sohn et al. 2003, 2006) among others. A summary of the arrays including their characteristics is given in Table 9.2. These arrays have been used to study C. albicans with regard to response to antimycotics and development of resistance, environmental stresses, hyphal development, host-pathogen interaction, biofilm formation and cell wall biogenesis as well as switching and mating among other studies (Fig. 9.1). Some of the results found in these studies are reviewed below. For a comprehensive review of the biology of C. albicans, see Calderone (2002).

Although most of these arrays are derived from the same genomic sequence, significant differences both in early and late established arrays as well as in the definition of ORFs resulted in microarrays which differ in their extent of gene specific probes predicted to be detectable. Furthermore, the different array facilities have designed distinct oligo sets or PCR-products for detection of the individual transcripts, which may result in differences in the detection of these transcripts. This is certainly one of the reasons for differences in the expression level and even the presence of individual genes between the individual arrays, which in some cases are evident. Nevertheless, the general picture of transcriptional profiling in general is comparable also when the different arrays developed in various laboratories have been used for similar experiments.

\section{A. Resistance Mechanisms to Antimycotics}

One of the most intensively studied topics in C. albicans is its defence mechanisms against antimycotics and the development of resistance. Several approaches to identify resistance mechanisms using transcriptomics are reported in the literature. One way is to directly confront $C$. albicans with the respective drug and monitor the change in gene expression. The first published transcriptomics study for C. albicans used this approach (De Backer et al. 2001). Another approach is to look at changes of gene expression in resistant clinical isolates or series of isolates with increasing resistance, e.g. (Rogers and Barker 2003). A third approach found in the literature is to follow adaptation of C. albicans in experimental microbial populations to (sub)-inhibitory concentrations of an antimicrobial drug. This experiment mimicked the evolution of drug resistance and identified genetic changes which were accompanied by changes in gene expression that persisted in the absence of the drug, resulting in new constitutive patterns of drug resistance (Cowen et al. 2002).

\section{Response of $C$. albicans to Antimycotics}

The first publication on transcriptomics of C. albicans was on its response to itraconazole (De Backer et al. 2001). The microarray was generated by Incyte Genomics containing 6600 ORFs, which were identified from genomic DNA sequences and cDNA sequences. In this study CAI-4, a URA3 deficient strain generally used in the community was used (Fonzi and Irwin, 1993). Among other 
Table 9.2. Characteristics of genome-wide microarrays used for C. albicans transcriptomics reviewed in this chapter. The denotation within brackets in column 1 (Consortium/fabrication) is used within the text to identify the DNA-microarray used for the respective study

\begin{tabular}{|c|c|c|}
\hline Consortium/fabrication & Type & References/links \\
\hline $\begin{array}{l}\text { Jansen Research Foundation/Incyte } \\
\text { Genomics, USA (Incyte) }\end{array}$ & $\begin{array}{l}\text { Spotted PCR-products: } 6600 \text { ORFs } \\
\text { derived from genomic sequence } \\
\text { and cDNA sequences }\end{array}$ & De Backer et al. (2001) \\
\hline $\begin{array}{l}\text { European Galar Fungail Consor- } \\
\text { tium/Eurogentec SA (Ivoz-Ramet, } \\
\text { Belgium) (Eurogentec) }\end{array}$ & $\begin{array}{l}\text { Spotted PCR-products: } 6039 \text { putative } \\
\text { ORFs derived from assembly } 6 \text { of } \\
\text { C. albicans genome } \sim 300 \mathrm{bp} \\
\text { PCR-product of each ORF }\end{array}$ & $\begin{array}{l}\text { http://www.pasteur.fr/recherche/unites/ } \\
\text { Galar_Fungail/ }\end{array}$ \\
\hline $\begin{array}{l}\text { Biotechnology Research Institute, } \\
\text { National Research Council, Mon- } \\
\text { treal, Canada (BRI) }\end{array}$ & $\begin{array}{l}\text { Spotted PCR-products: several ver- } \\
\text { sions, starting with assembly } 4 \\
\text { (6580 ORFs greater } 250 \mathrm{bp}) \text { up to } \\
\text { assembly } 19 \text { (6002 ORFs). Latest } \\
\text { version: } 70 \text { mer oligonucleotide } \\
\text { probes } 6354 \text { potential ORFs }\end{array}$ & $\begin{array}{l}\text { http://www.irb-bri.cnrc.gc.ca/microarray- } \\
\text { lab/ }\end{array}$ \\
\hline $\begin{array}{l}\text { Rupp Lab, Fraunhofer IGB, Stuttgart, } \\
\text { Germany (IGB) }\end{array}$ & $\begin{array}{l}\text { Spotted PCR-products: } 7200 \text { orfs } \\
\text { ( }<100 \text { base pairs). ORFs derived } \\
\text { from assembly } 6 \text { of C. albicans } \\
\text { genome, } 300-600 \mathrm{bp} \text { PCR-product } \\
\text { for each ORF }\end{array}$ & http://www.igb.fraunhofer.de/ \\
\hline $\begin{array}{l}\text { Agabian Lab, UCSF/Affymetrix, USA } \\
\text { (Affymetrix) }\end{array}$ & $\begin{array}{l}\text { Custom high-density oligonucleotide } \\
\text { Genechip: } 13025 \text { probe sets; these } \\
\text { probe sets reflect } 7116 \text { large ORFs } \\
\text { (<100 amino acids), } 247 \text { structural } \\
\text { RNA targets, } 4208 \text { unannotated } \\
\text { small ORFs }\end{array}$ & Lan et al. (2002) \\
\hline $\begin{array}{l}\text { Fink and Johnson Labs, Whitehead } \\
\text { Institute and UCSF, USA (UCSF/ } \\
\text { WI) }\end{array}$ & $\begin{array}{l}\text { Spotted PCR-products: Primer design } \\
\text { and ORF amplification were per- } \\
\text { formed in collaboration between } \\
\text { A. Johnson, UCSF and G. Fink, } \\
\text { Whitehead Institute, giving } 10000 \\
\text { PCR products representing } \sim 6300 \\
\text { ORFs, with many ORFs represented } \\
\text { by more than one spot }\end{array}$ & Bennett et al. (2003) \\
\hline $\begin{array}{l}\text { Consortium for Candida DNA Micro- } \\
\text { array Facilities, USA (CCDMF) }\end{array}$ & $\begin{array}{l}\text { Spotted PCR-products: PCR-products } \\
\text { of } 6175 \text { unique } C \text {. albicans ORFs } \\
\text { derived from assembly } 6\end{array}$ & Bensen et al. (2004) \\
\hline Operon (Operon) & 70mer oligonucleotide & $\begin{array}{l}\text { http://www.operon.com/arrays/oligosets_ } \\
\text { yeasts_overview.php }\end{array}$ \\
\hline
\end{tabular}

genes, this study revealed a global up-regulation of the ERG genes, in agreement with studies showing that the target of the azoles is the ergosterol biosynthetic pathway. In addition changes were observed in cell wall maintenance genes, lipid biosynthesis and gene products involved in vesicular transport. Interestingly induction of multi-drug transporters was not observed under the conditions used $(24 \mathrm{~h}$ incubation with $10 \mu \mathrm{M}$ itraconazol in synthetic glucose medium). Over all, treatment of cells with $10 \mu \mathrm{M}$ itraconazole resulted in 296 responsive genes. For 116 genes transcript levels were decreased at least 2.5-fold, while for 180 genes transcript levels were similarly increased. The ERG genes ERG11 and ERG5 were found to be up-regulated approximately 12 -fold. In addition, a significant up-regulation was observed for $E R G 6$, ERG1, ERG3, ERG4, ERG10, ERG9, ERG26, ERG25, ERG2, IDI1, HMGS, NCP1 and FEN2, all of which are genes known to be involved in ergosterol biosynthesis.

Liu et al. (2005) examined changes in the gene expression profile of $C$. albicans following exposure to representatives of the four currently available classes of antifungal agents used in the treatment of systemic fungal infections, the azoles, polyenes, echinocandines and nucleotide analoga. The most remarkable finding of this study is that none of the differentially regulated genes found exhibited similar changes in expression for all 

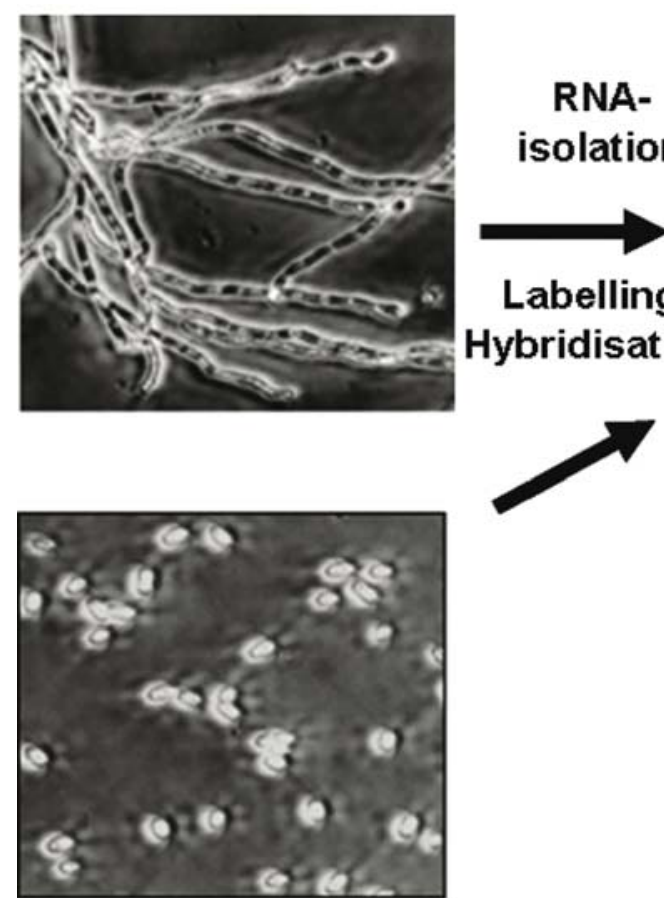

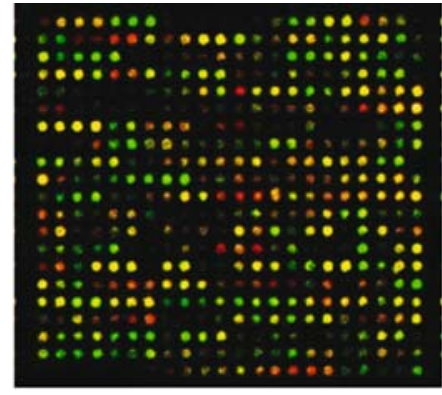

Data $\sqrt{\text { Analysis }}$

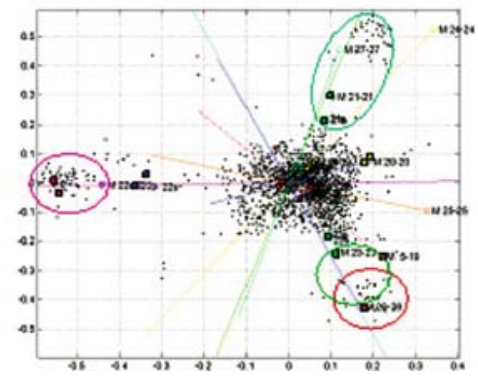

Fig. 9.1. Principle of transcriptomics. Cells are grown under two conditions of interest, e.g. yeast and hyphal growth conditions. RNA is isolated from cells grown under both conditions, labelled and co-hybridized to DNA- microarrays (for Affymetrix GenChips each labeled mRNA population is hybridized separately). Data analysis can be performed using clustering algorithms, e.g. correspondence analysis as shown here (Fellenberg et al. 2006) four drugs. Therefore, the response to the individual drug seems to be highly specific. This result could give an explanation for the observed benefit of combinatorial treatments due to the additive effect of multiple cellular defects induced by the combination of drugs. The experiments were conducted using microarrays manufactured by Eurogentec. SC5314 was grown in synthetic complete dextrose medium at a drug concentration corresponding to the $\mathrm{IC}_{50}$. All genes deviating by a factor of at least 1.5-fold from SC5314 incubated without the respective drug were defined as differentially expressed genes.

For each of the conditions used the authors identified a number of differentially regulated genes, ranging from 82 for incubation with ketoconazole (KTZ), 256 for incubation with Amphotericin B (AMB), 439 for incubation with 5-flucytosine (5-FC), up to 480 for incubation with Caspofungin $(\mathrm{CPF})$. Only two of the genes responded similar to $\mathrm{AMB}, \mathrm{KTZ}$ and CPF. These were DDR48, a gene known to be responsive to stress, and FET33 encoding for a ferroxidase required for high affinity iron uptake. Approximately 60 genes responded similar to
$\mathrm{AMB}$ and $\mathrm{CPF}$. This included the down-regulation of genes involved in iron regulation (CFL1, CFL2, FTR1, FTR2, CTR1, FTH1), chromatin/chromosome structure (HHF21, HHT21, HHF22, HTA1, HHT3, HTB1, NHP6A), and lipid, fatty acid and sterol metabolism (ERG25, ERG251, SAH1, ERG3, OPI3, ERG13, FAS1, $E R G 9)$. The authors speculated that these commonly differentially expressed genes reflect a response to a compromised cellular integrity, as both $\mathrm{AMB}$ and $\mathrm{CPF}$ are fungicidal agents. Other combinations found were marginal in number.

The response to the individual drugs was also described in detail. KTZ exposure increased the expression of genes involved in lipid, fatty acid and sterol metabolism, including NCP1, MCR1, CYB5, ERG2, ERG3, ERG10, ERG25, ERG251 and ERG11 (the azole target). KTZ also increased expression of several genes associated with azole resistance, including CDR1, CDR2, IFD4 (CSH1), DDR48 and RTA3. In agreement with the study by De Backer et al. (2001) several genes were found in both studies including ERG2, ERG3, POT14 (ERG10), ERG11, ERG25, NCP1, CYB5, SAH1, DDR48, CWH8 and $C T R 1$. Differences in the results of these studies were 
explained by the authors by differences between the drugs used and the experimental designs employed (in the study by De Backer, C. albicans was exposed to itraconazole for $24 \mathrm{~h}$ ). Interestingly, there seems to be no UPC2 regulon in C. albicans as observed in Sac. cerevisiae (Agarwal et al.2003). In Sac. cerevisiae UPC2 is the transcriptional regulator for sterol uptake under anaerobic conditions (Vik and Rine 2001).

$\mathrm{AMB}$ produced changes in the expression of genes involved in small-molecule transport, especially up-regulation of ion transporters, including calcium (IPF11550, IPF11560), potassium (IPF9136), sodium (ENA21), zinc (ZRT2), and sulfate (SUL1) transport, indicative of ion loss across the plasma membrane. This is consistent with the role of AMB in disruption of the plasma membrane. Furthermore, genes involved in stress response were identified (YHB1, CTA1, AOX1, SOD2, GSH1), consistent with the role of AMP in causing oxidative stress (Sokol-Anderson et al. 1988). Also observed was a decreased expression of genes involved in ergosterol biosynthesis, including ERG26, ERG16, ERG11, ERG9, ERG25, ERG13, ERG251 and ERG3, the fatty acid biosynthesis genes FEN12, FAS1, FAS2 and $A C B 1$, and the phospholipid biosynthesis genes $\mathrm{CHO} 2$ and $\mathrm{OPI} 3$, indicative of the need of the cell to avoid the presence of ergosterol in the plasma membrane. In contrast to the study of Barker et al. (2004) who investigated in vitro generated strains resistant to AMB overexpression of ERG5, ERG6 and ERG25 -a- 11 facilitating the alternate production of sterols - was not observed.

CPF targets the cell wall by inhibition of $\beta-1$, 3 -glucan synthase. Therefore, consistent with its mechanism of action, it induced changes in expression of genes encoding cell wall maintenance proteins, including the $\beta$-1,3-glucan synthase subunit GSL22, as well as other cell wall maintenance genes including PHR1, ECM21, ECM33 and FEN12. The genes responsive to both $\mathrm{CPF}$ and $\mathrm{AMB}$ have been mentioned above. As these also include genes involved in lipid, fatty acid and sterol metabolism additional modes of action for CPF might be possible.

5 -FC increased the expression of genes involved in purine and pyrimidine biosynthesis, including YNK1, FUR1 and its target CDC21. The changes in gene expression observed in response to 5-FC exposure are consistent with a need for the cell to increase RNA, DNA, and protein synthesis, including uracil phosphoribosyltransferase and thymidylate synthetase.
The relationship between antimicrobial pharmacodynamics and gene expression was examined by Lepak et al. (2006) in order to gain insight into the mechanism of persisting fluconazole (FCZ) effects following drug exposure. The authors examined a $C$. albicans culture at two time-points ( $1 \mathrm{~h}, 3 \mathrm{~h}$ ) during drug exposure (4xMIC) and at two time-points after drug exposure $(6 \mathrm{~h}, 9 \mathrm{~h})$ using microarrays (BRI-Arrays). During FCZ exposure 126 genes were found to be up-regulated and 148 to be down-regulated (threshold 1.5-fold). During recovery from FCZ treatment, a much larger number of genes were up-regulated (1055) and 35 were found to be down-regulated.Among the genes with known function that were up-regulated during exposure, most were related to plasma membrane/cell wall synthesis (18\%) including nine genes of the ergosterol pathway, stress responses (7\%), and metabolism (6\%). The categories of down-regulated genes during exposure included protein synthesis (15\%), DNA synthesis/repair (7\%) and transport (7\%) genes. The majority of genes identified at the postexposure time-points again were from the protein $(17 \%)$ and DNA (7\%) synthesis categories. Three genes (CDR1, CDR2, $E R G 11)$ were examined in greater detail following FCZ exposure in vitro and in vivo using a neutropenic mouse model of disseminated candidiasis. Expression levels from the in vitro and in vivo studies for these three genes were congruent. $C D R 1$ and $C D R 2$ transcripts were reduced during in vitro FCZ exposure and during supra-MIC exposure in vivo. In the post-exposure period, the mRNA abundance of both pumps increased. For ERG11 the opposite effect was observed, expression increased during exposure and fell in the post-exposure period. The expression of the three genes responded in a dose-dependent manner. Post-antifungal effects could be observed neither in vitro nor in vivo in this study, in contrast to previous studies (Andes and van Ogtrop 1999). This study may define targets to exceed the drug effects or block recovery from the drugs.

\section{Transcriptional Profiling of Clinical Isolates Resistant to Antimycotics}

Rogers et al. (Rogers and Barker 2003) used a set of four isolates, selected from a set of 17 isogenic previously characterized clinical isolates, to investigate FCZ resistance (Lyons and White 2000; Pfaller et al. 1994; Redding et al. 1994; White 
$1997 a, b)$. In a preceding study two of the four isolates were investigated using a DNA-Microarray prepared by Incyte Genomics (Rogers and Barker 2002). In the second, more comprehensive study, a set of four matched clinical isolates (including the two previously studied) were investigated using a microarray manufactured by Eurogentec (Rogers and Barker 2003).

These studies identified groups of genes that are co-ordinately expressed with either $C D R 1$ and $C D R 2$ or $M D R 1$, or with genetic changes in the ERG11 gene across the set of isolates. These findings led to the suggestion that these sets of coordinately regulated genes may be controlled by common regulatory systems. Indeed, Coste et al. (2004) could show in a later study that TAC1 is a transcription factor representing a common factor for CDR1 and CDR2 (see below). Rogers and Baker identified a total of 32 genes to be up-regulated and 14 genes to be down-regulated between isolates 2-79 (sensitive to FCZ MIC $2 \mu \mathrm{g} / \mathrm{ml}$ ) and 12-99 (resistant $\geq 64 \mu \mathrm{g} / \mathrm{ml}$ ). These included genes previously shown to be up-regulated (CDR1, CDR2, MDR1, ERG2, GPX1, RTA3, IFD5, IPF5987, CRD2) and down-regulated (FET34) in this series. Besides changes in membrane metabolism and efflux pumps, this study could confirm a connection of azole resistance to iron metabolism (via FET34) and to oxidative stress response [via SOD5 (IPF1222) and CRD2]. Genes coordinately regulated with MDR1 encompass 14 genes up-regulated and 10 genes down-regulated, including the up-regulation of IFD1, IFD4, IFD5, IFD7, GRP2, DPP1, CRD2 and INO1 and the down-regulation of FET34, OPI3 and IPF1222. Interestingly, the expression of several of the ERG genes (ERG5, ERG13, ERG25) was not correlated with the expression of either CDR1 or CDR2 nor with $M D R 1$ in this set of clinical isolates.

The co-regulation of genes with respect to CDR1/2 or MDR1 expression as identified in clinical isolates (see above; Rogers and Barker 2003) asks for identification of the respective regulons. In order to define the regulons of these efflux pumps Karababa and co-workers (2004) directly confronted C. albicans strains with drugs specifically up-regulating either $C D R 1 / 2$ or $M D R 1$ and comparing the results to expression profiles of clinical isolates overexpressing either $C D R 1 / 2$ or $M D R 1$. For this purpose they compared the transcript profiles (Eurogentec array) of a laboratory strain (CAF2-1) exposed to fluphenazine, resulting in specific up-regulation of $C D R 1$ and $C D R 2$ (de
Micheli et al.2002) or to benomyl, resulting in specific MDR1 up-regulation (Gupta et al. 1998), with those of two matched pairs of azole-susceptible and -resistant strains overexpressing CDR1 and CDR2 (CDR isolates) or MDR1 (MDR isolates). The clini$\mathrm{cal}$ isolates were incubated without drugs (YPD at $30{ }^{\circ} \mathrm{C}$ ) and CAF2-1 was incubated without or with exposure either for $20 \mathrm{~min}$ to $10 \mathrm{mg} / \mathrm{l}$ of fluphenazine or for $30 \mathrm{~min}$ to $25 \mathrm{mg} / \mathrm{l}$ of benomyl (YPD, $30^{\circ} \mathrm{C}$ ). In each of the four experiments between 200 and 300 genes were differentially regulated by at least 2 -fold. However, only a small portion of all genes was found to be commonly regulated, indicating that in vitro drug-induced gene expression only partially mimics expression profiles observed in azole-resistant clinical strains.

Between fluphenazine-exposed cells and CDR isolates 42 commonly regulated genes $(8.6 \%$ of all regulated genes 2 -fold; 19 genes 4 -fold) could be identified. Most strongly induced besides CDR1 and CDR2 were IFU5, RTA3 (encoding putative membrane proteins), HSP12 (encoding heatshock protein) and IPF4065 (potentially involved in stress response). Four of these six genes, but not HSP12 and IPF4065, contain a putative cis-acting drug responsive element (DRE) in their promoters. Interestingly, five out of nine genes specifically induced by fluphenazine (4-fold) were potentially involved in stress response (CFL2, IPF6629, GRP2, IPF17282, SAS3), whereas three of the four genes specific for the clinical isolates were part of the ERG pathway (ERG3, ERG6, ERG 251).

Commonly regulated between benomyl-exposed cells and MDR isolates were 57 genes $(11.5 \%$ of all regulated genes 2 -fold; 23 genes 4 -fold). The most up-regulated besides MDR1 were genes with oxido-reductive functions such as IFD genes, IPF5987, GRP2 (belonging to the aldo-keto reductase family), IPF7817 $[\mathrm{NAD}(\mathrm{P}) \mathrm{H}$ oxidoreductase] and $I P F 17186$. This study revealed that for the benomyl specific gene induction 21 of the 29 genes identified (4-fold) contained a potential Cap1 binding site, a transcription factor known to be involved in oxidative stress response (Zhang et al.2000). Seven of these genes (IPF2897, IPF11105, PST2, IPF3264, SOD1, TTR1, TRX1) are potentially implicated in oxidative stress response. Five other genes included in this cluster play a role in other stress responses. Among the 17 commonly regulated genes, nine are also involved in oxidative stress response (PYC2, GPX1, GRP2, IPF7817, IFD1, IFD4, IFD5, IFD7). 
Karababa et al. compared their results also to the studies from Rogers et al. (Rogers and Barker 2003) and Cowen et al. (2002; see above). They found onlyverylimited overlap between the individual results. Between the clinical isolates up-regulating the CDRs, five commonly identified genes were found CDR1, CDR2, RTA3, IFU5 and GPX1. These genes are also among those that are also commonly regulated between the fluphenazine and the CDR experiment of this study. Since four of these five commonly regulated genes contained a drug response element (DRE) in their promoter, these results strongly suggest the existence of a common transcriptional pathway important for their regulation. This transcription factor could later be identified as TAC1 (Coste et al.2004).

When comparing the set of genes commonly regulated in isolates up-regulating MDR1 only eight genes were commonly up-regulated in the three studies: MDR1, GRP2, IFD1, IFD5, IPF5987, GDH3, ARO8 and SNZ1. Besides the antifungal drug resistance function of $M D R 1$, the other genes have oxido-reductive functions (GRP2, GDH3, IFD1/5) or are potentially involved in pyridoxine (vitamin $\mathrm{B}_{6}$ ) synthesis (IPF5987, SNZ1).

Since $M D R 1$ can be also induced by $\mathrm{H}_{2} \mathrm{O}_{2}$, Karababa and co-workers compared their MDR1related results with a study published by Enjalbert et al. (2003) investigating the response of C. albicans to $\mathrm{H}_{2} \mathrm{O}_{2}$. They could show further parallels between MDR1 up-regulation, benomyl and oxidative stress response. IFD 1, GRP2, IFD 5, IFD 4 and IFD7 were induced more than 4 -fold under these three conditions, whereas GRP4, IPF12303, IFR2, TTR1, IPF13081, PST2 and IPF20104 were found induced only in benomyl and $\mathrm{H}_{2} \mathrm{O}_{2}$ response.Again, most of these genes are implicated in response to stress or have oxido-reductive functions. Among these, GRP2, GRP4, IPF12303, TTR1, PST2 and IPF20104 contain a putative Cap1 binding site in their promoters. Therefore, a functional linkage involving Cap1 probably exists between benomyl and $\mathrm{H}_{2} \mathrm{O}_{2}$ exposure.

The transcription factor responsible for regulation of the $C D R 1 / 2$ regulon, $T A C 1$, was identified by Coste and co-workers (2004) based on homology search in the genome for zinc-finger transcription factors. Tac1 was shown to bind to the DRE element located upstream of $C D R 1$ and $C D R 2$ as well as other genes induced by antifungals. Both, strains deleted for TAC1 as well as clinical isolates containing dominant alleles of TAC1 were investigated by DNA-microarrays (Eurogentec) in order to identify genes regulated by Tac1. The authors compared genes up-regulated in a clinical isolate (DSY296, azole-resistant) against its progeny (DSY294, azole-susceptible) as well as in a strain deleted for TAC1 carrying either an activated TAC1-2 allele (derived from DSY296) or TAC1. Furthermore, the response of the strain CAF2-1 to fluphenazine was monitored in the presence or absence of TAC1. Only four genes were commonly regulated in the microarray experiments: $C D R 1$, $C D R 2$ and RTA3 (probable transmembrane protein similar to Sac. cerevisiae YOR049c), all containing a consensus DRE in their promoters, and HSP12 (heat-shock protein). In addition IFU5, which was identified previously as a DRE-containing gene (de Micheli et al. 2002), was confirmed as regulated by TAC1 using Northern blotting in this study.

These results are in accordance with the studies by Karababa et al. (2004), Rogers et al. (Rogers and Barker 2003) and Cowen et al. (2002).

\section{Experimental Induction of Resistance}

Cowen et al. (2002) have used DNA-microarrays (BRI Array with 5,000 ORFs) to examine changes in gene expression during experimental acquisition of resistance to FCZ. The changes in gene expression were followed in four replicate populations (D8, D9, D11, D12) during 330 generations of evolution characterized previously (Cowen et al. 2000). The MIC for FCZ could be induced from $0.25 \mu \mathrm{g} / \mathrm{ml}$ to $4 \mu \mathrm{g} / \mathrm{ml}$ (D8, D12) or $64 \mu \mathrm{g} /$ $\mathrm{ml}$ (D9, D11) respectively for two of the populations. Interestingly reversion from high resistance $(64 \mu \mathrm{g} / \mathrm{ml})$ at generation 260 to reduced resistance at generation $330(4 \mu \mathrm{g} / \mathrm{ml})$ was observed for one of the cultures (D12). The final culture (D12-330) showed a higher fitness in the presence of the drug than its ancestor. In the absence of the drug (YPD, $\left.30{ }^{\circ} \mathrm{C}\right) 301$ genes whose expression was at last 1.5fold different over all populations were identified. Cluster analysis showed that in the final outcome three of the four populations $(D 9,11,12)$ grouped together whereas a forth population (D8) evolved differently. A third cluster reflected the early stage of adaptation. For D8 in total eight different ORFs could be identified as up-regulated, of which $C D R 2$ is known to be implicated in drug resistance (CDR1 was not present on the array). For D9, D11 and D12 at generation 330 a significantly larger number of genes were deregulated (up to 124 from 
301 genes). All of them showed overexpession of $M D R 1$. The nine genes showing the largest change in expression in the microarray experiments were ADH4, MDR1, YPL88, YPX98, YPR127W, GRE99, YNL229C, HYR1 and HSP12. The expression of these genes including $C D R 2$ were screened in 30 clinical samples with MICs of FCZ $>4 \mu \mathrm{g} / \mathrm{ml}$ and could be clustered in the same three patterns of gene expression. More than half of the isolates (17 of 30) clustered with D8, nine clinical isolates clustered with the control population that evolved without the drug and four samples of which three derived from one patient are similar to the earlyand late-stage pattern of D9, D11 and D12.

Besides $M D R 1$ and $C D R 2$, a set of genes ( YPL88, YPX98, YPR127w, ADH4) implicated in oxidative stress was found. The authors speculate that they may contribute to drug resistance because the azoles sensitize fungal cells to oxidative metabolites through inhibition of the target (a cytochrome P450 enzyme) in the ergosterol biosynthesis pathway (White et al. 1998). In contrast to other studies in fungi (Bammert and Fostel 2000; De Backer et al. 2001), only a moderate transcriptional modulation of the ERG pathway was observed in this study (for ERG1, ERG3, ERG11, ERG13).

Resistance of $C$. albicans to AMB was generated in a study by Barker et al. (2004) by growing SC5314 in the presence of increasing concentrations of the drug. Interestingly, cross-resistance to FCZ in the resistant strains generated was observed, as reported previously for a clinical isolate (Kelly et al. 1997). The MICs for the resistant isolate created were $>32 \mathrm{mg} / \mathrm{l}$ for $\mathrm{AMB}$ and $>256 \mathrm{mg} / \mathrm{l} \mathrm{FCZ}$. However, the doubling time for the resistant isolate SC5314-AR was $181 \pm 19 \mathrm{~min}$ as compared with $97 \pm 3 \mathrm{~min}$ for isolate SC5314, indicating a significant loss of fitness (as was confirmed by the loss of stability of the resistance after 28 doublings growth in the absence of $\mathrm{AMB}$ ). The changes in gene expression profile associated with the experimentally induced resistance to $\mathrm{AMB}$, were identified in microarray experiments (Eurogentec arrays). They identified 133 genes that were differentially expressed, by at least 2 -fold in SC5314-AR, with 27 genes up-regulated and 106 genes down-regulated. These experiments revealed overexpression of ERG5, ERG6 and ERG25, all facilitating the alternate production of sterols. Down-regulation of ERG genes was not observed. The sterol content of the resistant strain revealed that ergosterol was basically missing in the membrane fraction and replaced mainly by lanosterol and euburicol (24-methylene lanosterol), explaining the resistance against AMB. The synthetic pathway to lanosterol involves ERG1 and ERG7 but not ERG11, explaining the cross-resistance against Fluconazole. Again stress response genes like $D D R 48$ and iron transporters like FTR 1 and FET34 were found to be induced. The majority of genes down-regulated represent genes involved in protein synthesis, especially genes encoding for ribosomal proteins, which is in agreement with its slow-growth phenotype.

\section{Antimycotics for Topical Applications}

Besides antifungals used against systemic infections the reaction of $C$. albicans to ciclopirox olamine, a drug used for treatment of superficial mycoses was investigated by two groups using microarrays (both from Eurogentec). Ciclopirox is a topical antifungal agent of the hydroxypyridone class. Sigle et al. (2005) investigated the reponse of $C$. albicans in Sabouraud glucose medium at subinhibitory concentrations of ciclopirox $(0.6 \mathrm{mg} / \mathrm{l})$. Only 25 genes were found to be induced by more than 2 -fold and 21 genes were repressed by more than 2 -fold. The vast majority of the upregulated genes (15 genes) were involved in iron metabolism. These included known genes encoding iron reductases (CFL1), iron permeases and transporters (FTR1, FTR2, FTH1) which were previously found (Niewerth et al. 2003) and genes possibly involved in iron metabolism that have not yet been described in C. albicans (CFL2, CFL12, FET5, FET32, FET33, FET34, FRE5, FRE31, FRE32). Furthermore, a number of genes were identified encoding proteins similar to the GPI protein Rbt5 (RBT5, RBT2, IPF12101, CSA1) which has been reported to be involved in utilization of haemin and haemoglobin as iron sources (Weissman and Kornitzer 2004). These results in combination with microbiological assays led to the conclusion that ciclopirox acts as an iron chelator. Consequently, addition of iron ions strongly reduces the inhibitory effect of ciclopirox. Additional experiments showed that cells with induced oxidative stress proteins or grown in the absence of glucose were less susceptible to ciclopirox. This study indicates that metabolic activity, oxygen accessibility and iron levels are critical parameters in the mode of action of ciclopirox olamine. 
A parallel study of Lee et al. (2005) came to similar conclusions. Lee et al. used the same strain, C. albicans SC5314, but a different medium (synthetic dextrose) and ciclopirox olamine concentration were used [equivalent to the $\mathrm{IC}_{50}(0.24 \mathrm{mg} / \mathrm{l})$ for $3 \mathrm{~h}$. A total of 49 genes were found to be responsive to ciclopirox olamine (cut off: 2 -fold), including 36 up-regulated and 13 down-regulated genes. These included genes involved in small molecule transport (HGT11, HXT5, ENA22, PHO84, CDR4), iron uptake (FRE30, FET34, FTR1, FTR2, SIT1) and cell stress (SOD1, SOD22, CDR1, DDR48).

Comparing the induced genes found in both studies it is apparent that only nine of 25 or 36 upregulated genes have been found in both studies. These are RBT5, FET34.3eoc, FTR1, FTR2, FTH1, CCC2, CFL1, CSA 1 and IPF12101. All of these genes are involved in iron metabolism or potential cell surface proteins. The differences between both studies may be explained by different conditions, especially since media composition has been reported to have a strong effect on the activity of ciclopirox against $C$. albicans (Sigle et al.2005).

\section{B. Stress Response}

An appropriate stress response is thought to be one of the key elements for a pathogen to successfully colonize different niches of a host and to escape the host's defence mechanisms. Several stresses have been imposed to C. albicans in vitro in order to study the mechanisms of stress response and compare it with other nonpathogenic fungi. These stresses include peroxides and nitric oxide, as these compounds are encountered by $C$. albicans during cellular defence mechanisms of the host. Furthermore, heat shock, NaCl/osmotic stress and heavy metal exposure have been analysed by transcriptional profiling. In addition, adaptation to different $\mathrm{pH}$ is a key feature for C. albicans inhabiting environments like the gut, the skin and the vaginal tract with strongly differing $\mathrm{pH}$ values.

One of the main questions investigated was whether C. albicans, like Sac. cerevisiae and Sch.pombe, has a general stress response resulting in cross-protection to various stresses or whether the stress response is regulated by direct response to the individual stress.

\section{General Stress Response in C. albicans}

Two publications by Enjalbert et al. $(2003,2006)$ address this question. In total four different stresses were analysed. They include heat shock, oxidative stress, osmotic stress and heavy metal stress (cadmium). In the first publication heat-shock response was triggered by a temperature shift from $23^{\circ} \mathrm{C}$ to $37^{\circ} \mathrm{C}$, osmotic stress by adding $0.3 \mathrm{M} \mathrm{NaCl}$ and oxidative stress by the addition of $\mathrm{H}_{2} \mathrm{O}_{2}$ to a final concentration of $0.4 \mathrm{mM}$. The second publication also triggered osmotic stress by $0.3 \mathrm{M} \mathrm{NaCl}$, however they used $5 \mathrm{mM} \mathrm{H}_{2} \mathrm{O}_{2}$ to induce oxidative stress and $0.5 \mathrm{mM} \mathrm{CdSO}_{4}$ for heavy metal stress. Furthermore, they focus more on the role of Hog1p, including profiling of mutants deficient in HOG1. The different experiments conducted were analysed on two distinct arrays (BRI, Eurogentec). After analysis of the data from these experiments, conducted under partially different conditions, distinct conclusions were drawn with regard to the existence of a general stress response in C. albicans. Whereas the first study (Enjalbert et al. 2003) clearly states that no general stress response is present in C. albicans, the second study (Enjalbert et al. 2006) comes to the conclusion that a limited core stress response exists as well in this organism. However, it was confirmed that $C$. albicans has diverged from corresponding stress response networks in other yeasts (the model yeasts Sac. cerevisiae and Sch. pombe) and that in C. albicans several pathways function in parallel to regulate the core transcriptional response to stress. One of the main reasons for this divergent conclusions in these two studies is that $C$. albicans seems to be rather resistant to some stresses in comparison to Sac. cerevisiae and Sch. pombe. The response to $5 \mathrm{mM}$ and $0.4 \mathrm{mM} \mathrm{H}_{2} \mathrm{O}_{2}$ respectively are significantly different in $C$. albicans, indicating that $0.4 \mathrm{mM} \mathrm{H}_{2} \mathrm{O}_{2}$ may not be sufficient for triggering oxidative stress response. Whereas 347 genes showed expression that was modified specifically in response to $5 \mathrm{mM} \mathrm{H}_{2} \mathrm{O}_{2}$, only 265 genes show altered expression at $0.4 \mathrm{mM} \mathrm{H}_{2} \mathrm{O}_{2}$. Genes involved in the detoxification of peroxide stress were induced generally under both conditions (CAP1, CTA1, GPX1, GST3, TRR1, TRX1). However, other subsets of genes were differentially induced, for example, genes involved in carbohydrate metabolism were only induced in response to high levels of peroxide stress (ICL1, GPM2, GSY1, MLS1, NTH1, PCK1), whereas the DNA-damage response appeared to be evoked specifically at low levels of $\mathrm{H}_{2} \mathrm{O}_{2}$ (HNT2, IPF4708, IPF4356, RGA2).

Comparing the results from the high $\mathrm{H}_{2} \mathrm{O}_{2}$ concentration, Cd stress, osmotic stress and heat-shock experiments from both studies, a set of nine induced 
core stress response factors was identified in the data set (induced 1.5-fold or more). These include ECM41, GLK1, GRP2, HSP12, HXT61, HSP31, orf19.675, AHP1 and orf19.7085. The proteins encoded by these genes have known or putative functions in carbohydrate metabolism (GLK1, HXT61), cell wall (ECM41, orf19.675), redox processes (GRP2, AHP1) and as chaperones (HSP12, HSP31).

There is considerably more overlap between the lists of stress-repressed genes in these experiments than within the stress-induced genes ( 34 vs 38 genes in both studies). This is not surprising because all the stresses have the common feature of reducing growth rates. The nature of the repressed common genes therefore reflects in general a reduction in growth. A significant proportion of these genes are involved in protein synthesis and RNA processing (e.g. IPF966, IPF3709, NOP4, NMD3, MRPL3, RCL1).

The role of $H O G 1$ was investigated in more detail (Enjalbert et al. 2006). Inactivation of HOG1 significantly attenuates transcriptional response to osmotic and $\mathrm{Cd}$-induced stresses. However, a less dramatic effect on the transcriptional response to oxidative stress was observed (actually none of the 46 HOG1 dependent genes also induced by $\mathrm{H}_{2} \mathrm{O}_{2}$ have a known antioxidant function). This is also reflected in the result showing that hog1 mutants are highly sensitive to osmotic stress but only sensitive to peroxides at high concentrations. In C. albicans CAP1 was shown already to be responsible for the resistance to oxidative stress at significantly lower levels of $\mathrm{H}_{2} \mathrm{O}_{2}$ (Alarco and Raymond 1999; Zhang et al. 2000). Hence, CAP1 is required for $C$. albicans to survive both low and high doses of peroxide stress, whereas HOG1 seems to be required only for the response to high levels of oxidative stress. This is consistent with previous reports that Hog1 is activated only in response to high levels of peroxide (Smith et al. 2004). In agreement with these findings CAP1 was found to be crucial for regulating genes involved in oxidative stress response like CTA1, IPF20104 (both core stress response genes) and IFR2 (responding to osmotic and oxidative stress) independently of HOG1.

Considering only three stresses, $\mathrm{Cd}$, oxidative and osmotic/ $\mathrm{NaCl}$ stress, 24 genes were identified in C. albicans as core stress response genes. When compared to the available transcriptional data on the response of Sac. cerevisiae and Sch. pombe to these stresses it was found that in Sac. cerevisiae 5-fold and in Sch.pombe 7-fold more genes constitute the core stress response. This is also reflected in cross-protection experiments. In C. albicans cross-protection experiments show a 2-fold increase of resistance after a mild heat stress followed by a strong oxidative stress and no improvement in survival in the case of the mild oxidative stress or hyperosmotic stress followed by a strong heat shock (Enjalbert et al. 2003). Thus, the acquired resistance seems to be weak in C. albicans (maximum 2-fold) compared with the more than 100-fold increase in Sac. cerevisiae survival (Lewis et al. 1995).

Therefore, although there is a high degree of functional overlap in the global oxidative, osmotic and heavy metal stress response in the three yeasts, there has been significant divergence between the stress responses in these fungi. Especially with regard to a core stress response the available data indicate that it is rather limited in C. albicans and does not result in comparable cross-protection, as observed for Sac. cerevisisae. Interestingly, the functions of Msn2- and Msn4-related proteins, key elements of the core stress response in Sac. cerevisisae (O'Rourke and Herskowitz 2004), also appear to have been reassigned in C. albicans (Nicholls et al.2004), giving further evidence for the divergence of stress response mechanisms in these organisms.

Activation of Hog1 seems also to be distinct in C. albicans when compared to Sac. cerevisiae in which Hog1 is activated by the Ssk1 response regulator. Chauhan et al. (2003) found a divergent function for Ssk1 in C. albicans. Microarray studies showed that $C$. albicans utilizes the Ssk1 response regulator protein to adapt cells to oxidative stress, while its role in the adaptation to osmotic stress is less certain. Further, SSK1 appears to have a regulatory function in some aspects of cell wall biosynthesis. In C. albicans a deletion of SSK1 is not sensitive to osmotic stress imposed by the addition of sorbitol; however, significant sensitivity against oxidative stress was observed. Du and co-workers (2005) showed that an ssk1 mutant strain was more susceptible to killing by neutrophils than the wild type. Besides the high sensitivity to oxidative stress it was shown that the sensitivity of a $\Delta s s k 1$ strain to human defensin-1, one of the non-oxidative antimicrobial peptides of PMNs, was also greater than that of the wild type, demonstrating that non-oxidative killing in PMNs may contribute to the increased susceptibility of the ssk 1 mutant.

\section{Response to NO}

Nitric oxide is a key antimicrobial compound produced by the innate immune system (Fang 2004). 
Hromatka et al. (2005) investigated the reaction of $C$. albicans to this compound. The transcriptional response of $C$. albicans to $1.0 \mathrm{mM}$ DPTA NONOate (a chemical agent that releases NO in a $\mathrm{pH}$-dependent manner) in YPD was monitored in a time-course experiment over $120 \mathrm{~min}$ (UCSF/ WI array). They identified in total a number of 131 genes differentially regulated by a factor of at least two. Most of these genes are only transiently induced. All of the $\sim 65$ repressed genes returned to normal levels of expression by the $40 \mathrm{~min}$ timepoint. Only a group of nine genes, mostly involved in ion transport or redox processes, remains highly expressed throughout the $2 \mathrm{~h}$ time-course, including YHB1, AOX2, SSU1, YOL075c, YMR209c, CTR2, RBT5 and AOX1. YHB1, a flavohemoglobin, was most strongly induced by $\mathrm{NO}$ and its role in resistance to NO in vitro could be confirmed by deletion studies (see also Ullmann et al.2004). Furthermore, deletion of YHB1 resulted in prolonged induction of genes only transiently induced in the wild type and a set of additional genes involved partially in DNA damage repair, indicative of a main protective role of YHB1 for detoxification of NO. In addition, it was shown that deletion of YHB1 inappropriately activates parts of the filamentous growth pathway, as eight genes known to be hyphal specific were induced in YPD more than 6-fold, including HWP1, ALS3, RBT1 and ECE1. This is in agreement with the hyperfilamentous phenotype of the $\Delta y h b 1$ mutant strain. Interestingly, deletion of YHB1 resulted only in a moderate reduction of virulence in the tail-vein model of systemic infections in mice (Ullmann et al. 2004). More importantly it could be shown that mice lacking iNOS2, the main gene responsible for production of NO in the innate immune system, show no difference in susceptibility to C. albicans wild type or $y h b 1$ mutant strains, indicating that NO has no significant role in host defence mechanisms in a tail vein model of systemic infection in mice (Hromatka et al. 2005). Thus, the observed virulence defect for $\Delta y h b 1$ strains may not be attributed to increased sensitivity to NO.

Comparing the genes identified in this study as induced for at least $2 \mathrm{~h}$ in the presence of $\mathrm{NO}$ in wild type or $\Delta y h b 1$ strains with the genes defined as core stress-response genes by Enjalbert and co-workers (2006; ECM41, GLK1, GRP2, HSP12, HXT61, HSP31, orf19.675, AHP1, orf19.7085) it is apparent that none of the genes is part of the gene set describing the core stress response. However, the transcriptional response to DPTA NONOate of Sac. cerevisiae is reported to bear significant homologies to the response of $C$. albicans, including the induction of YHB1 and SSU1 (Sarver and DeRisi 2005).

\section{3. $\mathrm{pH}$ Regulation}

C. albicans encounters a multitude of different $\mathrm{pH}$ ranges in the different host niches it colonizes, starting from the oral cavity (in which highly fluctuating $\mathrm{pH}$ values occur due to nutritional uptake), to extremely acidic in the stomach $(\mathrm{pH} 2)$, less acidic in the duodenum ( $\mathrm{pH}$ 5), to alkaline in the intestine ( $\mathrm{pH} 7.7$ ) or acidic in the vaginal tract ( $\mathrm{pH} 4$ ). To counteract this $\mathrm{pH}$ stress, C. albicans has developed a system in which Rim101, a $\mathrm{pH}$-responsive transcription factor, plays a central role (Davis et al. 2000; Ramon et al. 1999). Bensen et al. (2004) investigated how Rim101 governs gene expression at pH 4 and pH 8 (M199 medium, $37{ }^{\circ} \mathrm{C}$ ) by comparing a rim101 deletion mutant with the wild type using whole genome microarrays (CCDMF). Comparing the transcriptome of the wild type at $\mathrm{pH} 4$ and $\mathrm{pH} 8$ identified differential regulation of 514 ORFs from 4715 detectable transcripts ( $<2$-fold). About half were down-regulated and the other half up-regulated at $\mathrm{pH} 8 / \mathrm{pH} 4$ respectively. Besides the known Rim-regulated genes like PHR2, RIM8, PHR1, PRA1 and RIM101 itself, a $\mathrm{pH}$-dependent bias was found for genes involved in hyphal growth, ion transport, protein synthesis and electron transport. Hyphal growthspecific genes were expected, since growth in M199 at $37^{\circ} \mathrm{C}, \mathrm{pH} 8$, promotes hyphal cell growth and growth at $37^{\circ} \mathrm{C}, \mathrm{pH} 4$, promotes yeast cell growth. The known hyphal-specific genes CSA1/ WAP1, ECE1, HWP1, HYR1, IHD1, RBT1, SAP4 and SAP6 were expressed 2- to 31-fold higher at $\mathrm{pH} 8$ compared with $\mathrm{pH} 4$. Seventeen ORFs upregulated at $\mathrm{pH} 8$ were classified as ion transporters, of which ten are predicted to function in iron transport, indicating that alkaline $\mathrm{pH}$ induces iron starvation. These include two high-affinity iron permeases (FTR1/2, FTH1), one multicopper oxidase (FET34), five ferric reductases (CFL1, FRE2, FRE7, FRE9, FRP2), one vacuolar iron transporter (SMF3) and one iron-siderophore binding protein (ARN1/SIT1) as well as CTR1, a copper transporter required for iron assimilation.

The contribution of Rim101 to this $\mathrm{pH}$-dependent gene regulation was determined by comparing the 
transcriptional profile of a RIM101 deletion mutant with the wild type at $\mathrm{pH} 8$ or $\mathrm{pH} 4$ (M199 medium, $37^{\circ} \mathrm{C}$ ). At pH 4 only eight genes showed a more than 2 -fold difference in the RIM101 deletion mutant, compared with the wild type. This indicates that Rim101 has no active role at $\mathrm{pH} 4$ under the conditions tested, which is in agreement with its inactive state and low expression level (Davis et al. 2000; El Barkani et al. 2000; Porta et al. 2001; Ramon et al. 1999). At pH 8, 186 genes showed a more than 2 -fold difference in the rim101 deletion mutant, compared with the wild type. Of these 186 genes 70 were not identified as $\mathrm{pH}$ regulated genes in wild type, 49 are alkaline repressed genes and 67 were alkaline induced genes. Thus, about a quarter of the genes deregulated in $\mathrm{M} 199,37^{\circ} \mathrm{C}$ at $\mathrm{pH}$ 8 by a rim 101 deletion are not primarily $\mathrm{pH}$-dependent but may serve other functions at alkaline $\mathrm{pH}$. Rim101 is responsible for both repression and activation of genes at alkaline pH. Rim101 dependent alkaline induced genes include the hyphal-specific genes CSA1/WAP1, ECE1, HWP1, HYR1, IHD1 and RBT1, as well as genes required for ion transport, especially for iron metabolism (ARN1, CTR1, ENA2, FET34, FRE2, FRE5, FRP2). Consequently, rim101 mutants are defective in hyphal development at M199, pH 8, 37 ${ }^{\circ} \mathrm{C}$ and show high sensitivity to iron starvation under these conditions. Thus the authors conclude that one important new aspect of the Rim101p-dependent alkaline $\mathrm{pH}$ response is to adapt to iron starvation conditions (for a more detailed study on iron metabolism, see Lan et al. 2004).

In Sac. cerevisiae it is known that Rim101 partially acts through Nrg1 (Lamb and Mitchell 2003). Bensen and co-workers investigated the relation between Nrg1 and Rim101 in C. albicans. In epistatic experiments strains deleted for RIM101, NRG1 or both were tested for hyphal growth on M199, pH 8 plates ( 5 days, $37^{\circ} \mathrm{C}$ ). The authors conclude from their results that Rim101 does not act through Nrg1 as the case of Sac. cerevisiae.

In a publication focusing on Rim101 binding sites Ramon et al. (Ramon and Fonzi 2003) described only 20 genes identified as deregulated in a rim101 mutant strain that was incubated in M199 medium ( $\left.\mathrm{pH} 7.5,28^{\circ} \mathrm{C}, \mathrm{OD}_{600}=0.6-0.7\right)$ and compared with the wild type using genome-wide microarray analysis (BRI arrays, Candida Chips 5.2). The genes found overlap with the genes identified by Bensen et al. (2004). As described by Bensen et al., based on the microarray analysis performed, NRG1 expression was not influenced by RIM101 under the conditions used in this study.
However, Lotz et al. (2004) found that that Rim101 and Nrg1 do interact. In their initial analysis a limited microarray focused on genes encoding for putative cell wall proteins was used to investigate the Rim101 mediated effect on the cell wall. Using both, a deletion mutant of rim101 as well as the dominant active allele RIM101-1426, it could be shown that the level of Rim101 activity inversely correlates with the level of $N R G 1$ transcript ( $\alpha$-MEM medium, $\mathrm{pH} 4.5$ or $7.4,25^{\circ} \mathrm{C}$ or $37^{\circ} \mathrm{C}$ ). Dominant active Rim101 results in a strong decrease in NRG1 mRNA under all conditions tested, most strongly at low temperatures and low $\mathrm{pH}$ values where NRG1 levels are high in the wild type. In contrast, deletion of RIM101 resulted in an increase in NRG1 transcript levels when compared with the wild type, most strongly at $\mathrm{pH}$ 7.4. In parallel to Rim101 activity, transcript levels of $H W P 1$ and $R B T 1$ are induced. For RBR1/PGA20, RBR2/PGA21 and $R B R 3$ the opposite pattern was observed, namely activated Rim101 blocks their expression, whereas NRG1 is required for their expression. Thus Rim101activity, directly or indirectly, regulates NRG1 transcript levels under the conditions used in this study. Thus the balanced regulation of RIM101 and NRG1 expression contributes to the control of the hyphal specific genes investigated.

Comparing the list of hyphal induced genes regulated by Rim101 with the genes identified as repressed by Nrg1 or Nrg1 and Tup1 (Kadosh and Johnson 2005) highlights the genes ECE1, HYR1, $H W P 1, I H D 1$ and RBT1 as co-regulated by these repressors and Rim101. In addition, $P H R 1$ also was identified as repressed by $\mathrm{Nrg} 1$ and Tup 1, as well as RNH1, PGA58, orf6.5146, DDR48, HIS1, PGA 13 and $A R G 1$ which are also regulated by Rim101. This indicates that for expression of hyphae-specific (cell wall) genes, there seems to be an interaction between Rim101 and Nrg1. For other functions described for Nrg1 and Rim101 this seems to be not the case. A direct comparison of the transcriptomes of Rim101, Nrg1 and Rim101/Nrg1 deletion strains might further clarify the relation of these transcription factors in C. albicans.

\section{Polymorphism of C. albicans}

C. albicans is a polymorphic organism occurring in several distinct morphologies, including yeastform cells or blastospores, chlamydospores, pseudohyphal growth forms and true hyphae (Sudbery et al. 2004). Depending on the environmental 
conditions C. albicans is able to change from one to the other growth form. The regulation of morphogenesis is governed by a multitude of signalling pathways, most of which have been reported to be of relevance for virulence (Liu 2001, 2002; Whiteway and Oberholzer 2004). The polymorphism of C. albicans is one of the key features of this organism and has been shown to be critical for pathogenesis. Mutants which are predominantly in the yeast form or in a pseudohyphal/hyphal morphology have been show to be strongly attenuated in virulence (Braun and Johnson 1997; Lo et al. 1997). Therefore, the molecular mechanisms underlying morphogenesis are of major interest. Several aspects have been selected for this review, focusing on the basic transcriptional changes during the yeast-to-hyphal transition, some of the transcription factors involved, the cAMP pathway and white-opaque switching and mating.

\section{Yeast to Hyphae Transition}

One of the first studies using microarrays containing an almost complete set of predicted ORFs (BRI, 5668 ORFs, based on assembly 4) was presented by Nantel et al. (2002). A goal of this study was to determine the genes which are differentially regulated during transition from the yeast to hyphal growth form and the contribution of Efglp and Cph1p, two transcription factors relevant for morphogenesis and virulence (Lo et al. 1997). Efg1 was shown to be a central regulator of virulence and morphogenesis, which is regulated via the cAMP pathway (Bockmuhl and Ernst 2001), whereas Cph1 was shown to be regulated by a MAPK pathway involved in morphogenesis and mating (Lane et al. 2001; Liu 2002).

Hyphal induction was performed by the addition of serum to rich medium (YPD $30^{\circ} \mathrm{C}$, to YPD $37{ }^{\circ} \mathrm{C}+$ fetal calf serum; FCS) and by a shift of Lee's-medium from $25^{\circ} \mathrm{C}$ to $37^{\circ} \mathrm{C}$. In addition, the effect of temperature induction alone (in YPD) or addition of serum at $25^{\circ} \mathrm{C}$ (where no hyphal development is observed) was monitored to exclude genes not involved in morphogenesis but responding to a shift in temperature or serum itself. Data analysis revealed that 18 genes were consistently induced by at least 2-fold (additional 56 genes by a factor of 1.5), whereas 46 genes were consistently down-regulated (1.5-fold) $6 \mathrm{~h}$ after the shift to the hyphal conditions employed. Besides previously identified hyphal specific genes, like HWP1, ECE1,
SAP4-6 or RBT1 among others, this study identified genes connected to actin remodelling PFY1 (profilin) and RDI1(inhibitor of Rho-GTPases) the secretory pathway (SEC24 and YBL060w), SOD5 a previously undescribed superoxide dismutase (see also Fradin et al. 2005) as well as ORFs without homologies to known proteins. Interestingly, $R B T 1$ and ECE1 respond to serum at low temperatures under conditions when C. albicans is not in a hyphal growth form, thus excluding them from the strictly morphogenesis-related genes.

The genes most strongly down-regulated were genes of unknown function ( $R H D 1,2,3$ repressed by hyphal development), cell surface proteins (FLO1, CSP27), a set of genes involved in lipid metabolism (YER73, YKR70, DAK2, SOU1, PLB1), DNA-binding proteins (NRG1, GIS2, CBF1, YDR73, TYE7, CUP9) as well as other functions: HSP12, CHT2, YHB1, RHR2, YLR63 and PCK1. For genes like CHT2 and RHD2, a down-regulation by a temperature shift from $30^{\circ} \mathrm{C}$ to $37^{\circ} \mathrm{C}$ without addition of serum was observed, identifying them as temperature-regulated genes rather than morphogenetic genes.

In a time-course experiment looking at the time-points $30 \mathrm{~min}$ and $60 \mathrm{~min}$ additional genes were identified which were only transiently expressed and therefore potentially relevant for the initiation of germ tubes. In total 232 genes were reported to show significant variation at the time-points investigated. These include chaperones encoded by WOS2, RAD14, YNP115 and $C Y P 2$, as well as proteins like a BEM2 homolog, a Rho1-GAP involved in cell wall maintenance and Rho3p, a small GTPase involved in cell polarity. The majority of the genes transiently down-regulated encode proteins involved in translation.

The role of EFG1 and CPH1 in morphogenesis was addressed by transcriptional profiling of the respective mutants deleted for theses transcription factors. Transcriptional profiling of mutants in EFG1 and $C P H 1$ revealed a change in the expression of 74 genes (30 genes induced, 44 genes repressed) in YPD at $30{ }^{\circ} \mathrm{C}$. Some of the repressed genes have been shown in Sac. cerevisiae to be involved in stress response, including HSP12, GLK1, SNO1, ECM4 and GRE2. The transcriptional profiles of the efg1cph 1 mutant strain indicate that most of the hyphal induced genes do not respond to induction with serum at $37^{\circ} \mathrm{C}$. Instead, the transcriptional profile resembles the profile of the wild type after adaptation to $37^{\circ} \mathrm{C}$ 
(without serum), indicating that Efg1p and Cph1p are responsible for initiating the transcriptional response to serum (including hyphal development). In addition, it was found that Cph1p does not have a significant EFG1-independent role in yeast morphology under the conditions tested.

A similar result was found in a study investigating specifically cell wall biogenesis during the yeast to hyphal transition in dependence of EFG1 and $C P H 1$. Sohn and co-workers (2003) used two hyphae-inducing conditions (YPD, $37^{\circ} \mathrm{C}+$ serum, or $\alpha$-MEM, $37^{\circ} \mathrm{C}$ ) and two yeast form inducing conditions (YPD, $30{ }^{\circ} \mathrm{C}$, or $\alpha-\mathrm{MEM}, 25^{\circ} \mathrm{C}$ ) to investigate the transcriptional profile of 117 genes involved in cell wall biogenesis in SC5314 as well as in strains deleted for $C P H 1, E F G 1$, or both transcription factors. As reported by Nantel et al. (2002) Cph1p did not have a significant EFG1-independent role. In addition it was found that Efglp is a major regulator of cell wall biogenesis. This study revealed a high variability of the cell wall transcriptome under the conditions tested and could identify both yeast-form-specific and hyphae-specific transcripts of potential cell wall genes. About $60 \%$ of all genes present on the array were changed by more than 2-fold under at least one of the conditions investigated. As hyphal specific genes up-regulated under the hyphal inducing conditions used HWP1, RBT1, RBT4, HYR1, HWP2 (ORF6.2933), CHS4 and ORF6.2071 were identified. Deletion of EFG1 resulted both in the repression as well as in the induction of potential cell wall genes, indicating a dual function of Efg1 as repressor and activator of gene expression. This was shown in detail for the newly described genes HWP2 and YWP1, whose expression depended on the presence of EFG1 and for $R B E 1$ which is only expressed significantly in the absence of Efg1. The major changes of the cell wall composition observed in an EFG1 mutant, as implicated from this study, is well in agreement with the reduced adhesion observed for strains deficient in Efg1 (Dieterich et al. 2002) and helps to rationalize the reduced pathogenicity of these strains observed in mouse models of systemic infections (Lo et al. 1997).

\section{The APSES Proteins Efg1 and Efh1 in C. albicans}

In $C$. albicans two genes encoding APSES proteins (named after the members of the family all encoding fungal transcription factors involved in morphogenesis) are present: EFG1 and EFH1. The function of both genes was studied in detail using DNA-microarrays (Eurogentec) initially also focusing on morphogenesis (Doedt et al.2004). In contrast to Nantel et al. (2002) in this study the early stage of hyphal induction $(30 \mathrm{~min})$ and its dependence on the APSES proteins was investigated.

The function of EFG1 and EFH1 were investigated both in rich medium and under hyphaeinducing conditions by comparing the respective deletion strains to the wild type. Genome-wide transcriptional profiling revealed that $E F G 1$ and EFH1 regulate partially overlapping sets of genes associated with filament formation. Most interestingly, Efg1p not only regulates genes involved in morphogenesis but also strongly influences the expression of metabolic genes, inducing glycolytic genes and repressing genes essential for oxidative metabolism. By using one- and two-hybrid assays, it was furthermore demonstrated that Efglp acts as a repressor of transcription, whereas Efhlp acts as an activator of gene expression.

In rich medium (YPD, $\left.30^{\circ} \mathrm{C}\right) E F G 1$ was found to modulate the expression of 283 genes by a factor of at least 1.5, with 100 being up- and 183 downregulated. Most interestingly deletion of EFG1 had a major impact on genes known to regulate carbon metabolism. From all genes deregulated in an efg 1 mutant strain $27 \%$ could be assigned to metabolism. Almost all glycolytic enzymes, like the key regulators FBA1 or PFK1, as well as genes required for the accumulation of reserve carbohydrate (TPS2, TPS3 among others) were repressed in the absence of Efg1, whereas genes encoding for enzymes of the TCA cycle were induced. Thus, the presence of Efglp favours fermentative and represses oxidative growth. Consequently, efg1 mutant strains are more sensitive to antimycin A, a drug blocking ATP synthesis via the respiratory chain. This is also in agreement with results by Lan et al. (2002) who showed that white cells had enhanced expression of glycolytic genes compared with the opaque cells favouring oxidative metabolism. Opaque cells require very low levels of Efg1p, whereas high expression levels of Efg1p induce white cells (Sonneborn et al. 1999; see below).

In contrast to $E F G 1$, only nine genes (eight upand one down-regulated) were found to be regulated by $E F H 1$ in $Y P D, 30^{\circ} \mathrm{C}$, indicating a minor role for Efh 1 under these conditions. This is reflected in the low transcript level of $E F H 1$ which is about 10-fold less than the transcript level of EFG1. 
The simultaneous deletion of EFG1 and EFH1 showed a transcriptional pattern that only partially overlapped with that of the efg1 single mutant (49 from 283 genes). The majority of the genes (233 genes) were deregulated only by efg 1 but not in the efg1 efh 1 double mutant, however, a new subset of 63 genes was affected in the efg 1 efh 1 double mutant that was not detected in the efgl or efh 1 single mutant. This result is indicative of synthetic interactions between EFG1 and EFH1. Synthetic phenotypes of the efglefh 1 mutant were observed for embedding and microaerophilic conditions. Basically, additional deletion of $e f h 1$ in an $e f g 1$ mutant strain resulted in reversion of the phenotype back to the wild type, consistent with the results from the transcriptional profiling experiments.

The effect of EFG1 and EFH1 on morphogenesis was also investigated in this study. In contrast to Nantel et al. (2002) hyphal induction was initiated by adding cells to YP $+10 \%$ horse serum for $30 \mathrm{~min}$ without the addition of glucose to the medium. Under this regimen 243 genes were affected in the efg1 strain (factor 1.5) and 39 in the efh 1 strain, again showing the predominat effect of Efglp. In a similar way as in YPD, $30^{\circ} \mathrm{C}$, the double mutant efglefh 1 revealed an additional set of 58 genes but also only 47 which were affected by deletion of $E F G 1$ alone. Again glycolytic enzymes were expressed at a lower level in cells lacking Efg1, but in this case the TCA cycle was not up-regulated, most likely due to the fact that no glucose was present in the medium ( $10 \%$ serum only). The induction of hyphal associated cell wall genes was observed in a similar way as reported (Nantel et al. 2002; Sohn et al. 2003). Differences in these data to the data generated by Nantel and co-workers may be due to the different experimental conditions used.

The effect of overexpression of EFG1 and EFH1 in $C$. albicans was also investigated. The use of the PCK1-promoter required the use of SSAC medium, a synthetic medium containing no glucose (Leuker et al. 1997). Overexpression of EFG1 resulted in the down-regulation of 53 and up-regulation of only 32 genes, indicating that Efglp predominantly acts as a repressor as indicated in a previous study (Sohn et al. 2003). Interestingly, only 14 genes identified in this experiment were also identified in strains deleted for EFG1 (as oppositely regulated). This may also be due to the significantly different growth conditions used for both experiments including the change of the main carbon source. Among these 14 genes, cell wall genes associated with hyphal devel- opment, HWP1, ALS10, RBT5, ECE1 and PHR1, as well as genes encoding stress-response proteins like DDR48 and SOD5 were identified. In contrast to EFG1 overexpression, EFH1 overexpression resulted in 53 up-regulated genes (including $H W P 1$, $A L S 10, E C E 1, D D R 48)$ and 28 down-regulated genes, indicative of a transcriptional activator. $E F H 1$ overexpression, like EFG1 overexpression, results in the formation of pseudohyphae, blocks true hyphae formation and triggers opaque to white switching, both of which requires EFG1.

Promoter activation studies in C. albicans using LexA-Efg1 and LexA-Efh1 fusions confirmed these results. Interestingly, in Sac. cerevisiae using a Gal4 DNA-binding domain, fusion to EFG1 did not result in repression of the corresponding promoter, indicating that additional cofactors from C. albicans are required to exert the repressing function of Efg1.

These results indicate that Efh1 supports the regulatory functions of the primary regulator, Efg1, supporting a dual role for these APSES proteins in the regulation of fungal morphogenesis and metabolism.

Cao et al. (2006) could show that FLO8 controls a subset of the genes controlled by EFG1. The $\Delta$ flo 8 mutant was shown to be avirulent in a mouse model of systemic infection, similar to a $\Delta e f g 1$ mutant. Genome-wide transcription profiling of $\Delta e f g 1$ and $\Delta$ flos using a C. albicans DNA microarray (70mer set by QIAGEN Operon) suggested that Flo8 controls subsets of Efg1-regulated genes. Most of these genes are hyphae-specific, including HWP1, HYR 1, ALS3, ALS10, RBT1, HGC1 and $I H D 1$. Most interestingly, all genes identified to be regulated by FLO8 are also regulated by EFG1 in a similar way but not vice versa. Consistent with this finding, it was shown by in vivo immune-precipitation that Flo8 interacts with Efg1 in yeast and hyphal cells. Similar to $\Delta e f g 1$ and $\Delta c d c 35$ (adenylate cyclase) strains, $\Delta$ flo 8 strains shows enhanced hyphal growth under an embedded growth condition. These results suggest that Flo8 may function downstream of the CAMP/PKA pathway and together with Efg1 regulate the expression of hyphae-specific genes in C. albicans.

\section{3. cAMP Signalling}

cAMP is a signalling molecule activating one of the major protein kinases, PKA, in fungi. Harcus and co-workers (2004) investigated the consequences of the absence of adenylyl cyclase (CDC35), RAS1 
and $E F G 1$ using transcription profiling (BRI array, 6002 ORFs). Cdc35 is the only known enzyme responsible for cAMP production in C. albicans which is activated in part by Ras1 (Rocha et al. 2001). Efg1, as describe above, has been proposed to be one of the key transcription factors regulated by the cAMP-PKA pathway (Bockmuhl and Ernst 2001). To investigate conditions inducing yeast and hyphal growth forms the respective deletion mutants were grown in $\mathrm{YPD}, 30^{\circ} \mathrm{C}$, or $\mathrm{YPD}+$ serum, $37^{\circ} \mathrm{C}$. Genes modulated by at least 1.4 -fold were selected and data from Nantel et al. (2002) and Lee et al. (2004) were analysed together with the data generated in this study. A collection of 1168 genes was identified as significantly modulated (1.4fold) under at least one of the conditions used. Under all conditions examined, the profiles of the ras 1 and $c d c 35$ mutants were similar to each other (in the same dendrogram sub-branch), whereas the profile of the efg 1 mutant was shown to be different. Morphologically, the three mutants were distinct: when growing in YPD, $37{ }^{\circ} \mathrm{C}+$ serum the efg 1 and $c d c 35$ mutants both remained nonhyphal whereas ras 1 was still able to form hyphae. Thus, transcription profiling provides a different picture of the relationships among the elements than did the cellular morphology.

Comparison of the $c d c 35$ mutant with the wild type resulted in the largest differences ( 600 transcripts in yeast form, 800 transcripts in hyphal growth conditions). The profiles from yeast and hyphal growth conditions correlated significantly. The majority of genes encoding for ribosomal proteins or for subunits of the RNA polymerase holoenzymes were repressed in the $c d c 35$ mutant. Similarly, the loss of CDC35 was associated with repression of metabolic pathways such as the TCA cycle, pyrimidine metabolism and the synthesis of heme and sterol. This reflects the reduced growth rate exhibited by the $c d c 35$ mutant. Besides a large number of genes without known homologs, a notable group of the transcripts elevated in the absence of cAMP encode proteins involved in the formation and function of the cell wall. In accordance with this finding the $c d c 35$ mutant tends to aggregate and was shown to be significantly more resistant than wild type cells to calcofluor white, which binds to chitin, as well as to zymolyase, which is primarily a $\beta$-1,3-glucanase. In addition a significant correlation was observed between the $c d c 35$ profile and the profile observed in osmotically shocked cells (Enjalbert et al. 2003). Cdc35 cells also exhibited an increased sensitivity to osmotic stress. Further results showed that, during the yeast-to-hyphal transition, almost all of the genes that were modulated in wild-type cells, including classic hyphae-induced genes such as ECE1, HWP1 and SAP4, are no longer responsive to the serum and heat signals in the $c d c 35$ mutant. This suggests that most of the response to a shift from $30^{\circ} \mathrm{C}$ to $37^{\circ} \mathrm{C}+\mathrm{FCS}$ in C. albicans is mediated by the cAMP pathway. However, a few transcripts, including CHA2, GAP4, HMO1, RHD1, RHD3, SNZ1

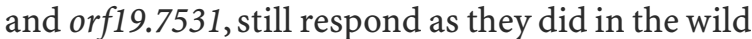
type, suggesting that a cAMP-independent pathway may contribute to morphogenesis.

The loss of Ras1p function was less severe than the loss of adenylyl cyclase. Only 72 transcripts were significantly more abundant in RAS1-deleted cells (YPD, $30^{\circ} \mathrm{C}$ ) than in the wild type, whereas four transcripts were less abundant ( 100 during hyphal induction conditions). The majority of the Ras1p-influenced transcripts are a subset of those that are modulated by cAMP (both for hyphal and yeast-form growth). Besides many of the genes of unknown function, a number of cell wall genes showed similar behaviour in ras 1 and $c d c 35$ cells. As observed for strains deleted for CDC35, ras 1 mutants showed increased resistance to zymolyase and calcofluor white. However, the ras1 mutant is not responsive to osmotic stress (both phenotypically and at the transcriptional level). The transcript levels of some of the hyphal-specific genes, such as $E C E 1, R B T 1$ and $H W P 1$, were clearly reduced when ras 1 was compared with the wild type in hyphal conditions. However, they were still partially responsive in the ras 1 whereas in the cdc35 mutant they were totally unresponsive.

Interestingly, Harcus and co-workers found that the majority of EFG1-modulated genes were distinct from those modulated by RAS1or CDC35. Efg1 had the strongest effect on gene expression during the yeast to hyphal transition (200 genes modulated), whereas during yeast growth only 85 genes were identified as modulated. Doedt et al. (2004) found a significantly larger number of genes modulated by Efg1, partially under the same conditions (283 genes in YPD, $30^{\circ} \mathrm{C} ; 243$ genes in $\mathrm{YP}+$ serum, $\left.37^{\circ} \mathrm{C}, 30 \mathrm{~min}\right)$. Both studies identified the genes required for glycolysis and gluconeogenesis modulated by Efg1, as well as a correlation with profiles of the white to opaque switch (Lan et al. 2002). For hyphal growth conditions, the small number of modulated transcripts that were 
commonly influenced in the efg $1, c d c 35$ and ras 1 mutants identified most of the highly modulated, hyphae-specific genes that were initially used to define this signalling pathway (e.g. HWP1, ECE1). The factors of induction or repression in this study, however, were in general lower than in other studies (e.g. Doedt et al. 2004; Kadosh and Johnson 2005). A reason for this has been proposed by Kadosh et al. (see below).

\section{Repression of Transcription \\ as Key for Morphogenesis}

Two publications described the global effect of transcriptional repressors on gene expression for the yeast to hyphal switch in C. albicans. Kadosh focused on the three transcriptional repressors Tup1, Nrg1 and Rfg1 (Kadosh and Johnson 2005), whereas Garcia-Sanchez focused on Ssn6, Tup1 and Nrg1 (Garcia-Sanchez et al. 2005).

Kadosh and Johnson compared the transcriptional changes of mutants deficient in Rfg1, Nrg1 and Tup1 to the wild type in yeast and hyphal growth conditions (UCSF/WI array; YPD, $30{ }^{\circ} \mathrm{C}$ or $37^{\circ} \mathrm{C}$, YPD + serum, $30^{\circ} \mathrm{C}$ or $37^{\circ} \mathrm{C}$, similar to Nantel et al.2002). It was pointed out that the status of the culture to inoculate the main culture was critical for the experiment. An overnight culture had to have $\mathrm{OD}_{600}>13$ if a high rate (close to $100 \%$ ) of filament formation was to be obtained. Otherwise only partial filamentation was observed. Consequently, analysis of these mixed cultures resulted in apparently reduced induction of filament-specific genes, whereas cultures with high levels of filamentation resulted in much higher induction rates of hyphae-specific gene expression.

DNA-microarray analysis identified 61 genes that are significantly induced ( $\geq 2$-fold) during the yeast-to-hyphae transition [YPD + serum, $37^{\circ} \mathrm{C}$, compared with the same time-points $(1,2,3,5 \mathrm{~h}$ time-points) in YPD, $30^{\circ} \mathrm{C}$. Approximately onethird of these genes are induced $\geq 10$-fold after $1 \mathrm{~h}$ (including ECE1, HYR 1, ALS10, ALS3, HWP1, SAP5, SAP4, PRY4, orf19.3698, POP4, IHD1, PHR1, USO6, orf19.1120, SOD5). Of the 61 genes identified in this study, ten correspond to the 18 genes (induced $\geq 2$-fold) identified by Nantel et al. (ECE1, SAP4,5, HWP1,SOD5, RBT1,DDR48,PHR1,YBL060w,IHD1). Most of them are part of the genes induced $\geq 10$ fold. Approximately half of the 61 genes are transcriptionally repressed in the yeast-form state by at least one of the three transcriptional repressors:
Rfg1, Nrg1, and Tup1. From these results, the authors conclude that the relief of transcriptional repression plays a key role in activating the C. albicans filamentous growth programme. Intriguingly, several of the highly induced genes found in this study, including ALS10, HWP1, ECE1, RBT1, SOD5, $D D R 48$ and $P H R 1$, are among the genes induced by overexpression of Efg1p (Doedt et al. 2004).

Garcia-Sanchez and co-workers (2005) characterized the regulons of the transcriptional repressors Ssn6, Nrg1, and Tup1 (Eurogentec Array). In Sac. cerevisiae Tup1-Ssn6 constitute a well defined co-repressor which is conserved from yeast to man (Redd et al. 1997). Overlapping sets of genes are a sign for co-regulation and therefore would indicate interaction between these factors. In contrast to Sac. cerevisiae, transcriptional profiling in C. albicans revealed only a small overlap between Tup1 and Ssn6. This is in agreement with the distinct phenotypes of a deletion in TUP1 or SSN6. Deletion of SSN6 promotes morphological events reminiscent of morphological switching rather than filamentous growth, whereas deletion of $T U P 1$, as well as deletion of NRG1, results in constitutive filamentation. Of 224 genes which were up-regulated in a $\Delta t u p 1$ strain, only 38 genes were coregulated in the $\Delta s s n 6$ strain, indicating that for the repression of 186 Tup1-regulated genes SSN6 is not necessary. Looking at down-regulated genes the discrepancy is even larger (only five of 117 TUP1-regulated genes are co-regulated with SSN6). The overlap with $\Delta n r g 1$ strain was similar, with a higher proportion of Nrg1 and Tup1 co-regulation than Nrg1 and Ssn1 co-regulation. Consistent with the study of Kadosh and Johnson (2005) the hyphae-specific genes HWP1, ECE1, RBT1 and $R B T 5$, as well as genes like $D D R 48$ and $A L S 10$ were identified as regulated both by NRG1 and TUP1. Other hyphae-specific genes like HYR1 were identified as TUP1-regulated. All of these genes were not found to be derepressed in the $\Delta s s n 6$ strain under the conditions used (YPD, $30^{\circ} \mathrm{C}$ ). [Hwang reported partial derepression of $H W P 1$ and ECE1 in YPD, $37{ }^{\circ} \mathrm{C}$ (Hwang et al. 2003a).] Genes coregulated by Tup1 and Ssn 6 were related to amino acid or carbon metabolism, like the key gluconeogenetic genes PCK1 and FBP1 as well as the glyoxalate cycle gene $M L S 1$. Phenotypic switching is also associated with changes in carbon metabolism and has been shown to depend on Efg1 (see above and Doedt et al. 2004; Lan et al. 2002). In addition the white-phase-specific gene $W H 11$ was 
shown (by Northern blot) to be repressed by Ssn6 but not by Tup1 or Nrg1.

These results show that Ssn6 and Tup1 in general play distinct roles in C. albicans. Nevertheless, both Ssn6 and Tup1 were required for Nrg1 mediated repression of an artificial NRE (Nrg1 Response Element) promoter, indicating that in some cases a Tup1-Ssn6 co-repressor exists, as in Sac. cerevisiae.

\section{Phenotypic Switching and Mating}

White-opaque switching in the human fungal pathogen $C$. albicans is an alternation between two quasi-stable, heritable transcriptional states observed in a few clinical isolates. This has been most extensively described in the patient isolate WO-1 (Slutsky et al. 1987). WO-1 alternates between white hemispherical colonies, designated white $(\mathrm{W})$, and grey flat colonies, designated opaque $(\mathrm{O})$. W/O phenotypic switching affects the shape and size of cells, their ability to form hyphae, their surface properties (e.g. adhesion, permeability), membrane composition, range of secretory products, sensitivity to neutrophils and oxidants, antigenicity and drug susceptibility (Soll 1997). Recently, it was shown that white-opaque switching and mating are both controlled by the mating type locus homeodomain proteins (Miller and Johnson 2002). The majority of C. albicans strains are heterozygous for the mating type locus MTL $(a / \alpha)$ and cannot undergo white-opaque switching (Lockhart et al. 2002). However, when these cells undergo homozygosis at the mating type locus (i.e. become $a / a$ or $\alpha / \alpha$ ), they can switch, and they have to switch in order to mate efficiently (WO-1 is MTL $\alpha / \alpha)$. Opaque cells were shown to mate approximately $10^{6}$ times more efficiently than white cells. These results showed that opaque cells are a mating-competent form of $C$. albicans and that this pathogen may undergo a white-to-opaque switch as a critical step in the mating process. As white cells are generally more robust than are opaque cells, this strategy may allow C. albicans to survive the harsh environments within a mammalian host, but still retain the ability to generate mating-competent cells.

For the analysis of switching Lan and co-workers (2002) analysed the transcriptome of both cell types (in WO-1) at four time-points $(12 \mathrm{~h}, 18 \mathrm{~h}, 24 \mathrm{~h}$, $48 \mathrm{~h}$; Lee's medium; Affymetrix GeneChip). A total of 373 ORFs demonstrated a greater than 2-fold difference in expression level between the switch phenotypes (in at least three time points); 221 ORFs were expressed at a higher level in opaque cells than in white cells; and 152 were more highly expressed in white cells. Affected genes represent functions as diverse as metabolism, adhesion, cell surface composition, stress response, signalling, mating type and virulence. Approximately one-third of the differences between cell types were shown to be related to metabolic pathways. Most interestingly, opaque cells were expressing a transcriptional profile consistent with oxidative metabolism and white cells were expressing a fermentative metabolism. This bias was obtained regardless of carbon source, suggesting a connection between phenotypic switching and metabolic flexibility. Efg1 seems to be involved in these events as it was shown previously that the expression level of Efg1 determines the phase of the cells (high Efg1 levels induce white cells; Sonneborn et al. 1999) and regulate metabolism (Doedt et al. 2004). EFG1 is primarily expressed in white cells which accordingly have a fermentative metabolism. In addition it was found that $\mathrm{W}$ and $\mathrm{O}$ cells differentially express genes presumed to function in mating-type differentiation and cell-type control. The $\alpha$-pheromone encoded by ORF6.4306, a homologue of the Sac. cerevisiae a-factor pheromone receptor (STE3) and a putative mating-type regulatory protein encoded by MTL $\alpha 1$ are all more highly expressed in O cells, consistent with WO-1 being equivalent to $M T L \alpha / \alpha$.

In contrast to mating in Sac. cerevisiae (Herskowitz 1989), Tsong and co-workers could show that in $C$. albicans each of the two mating type alleles $(a, \alpha)$ contributes a positive regulator of its respective mating type (a2, $\alpha 1$; Tsong et al. 2003). Additionally, each allele contributes one-half of a heterodimer that negatively regulates mating competency $(\mathrm{a} 1, \alpha 2)$. Each half of the heterodimer - on its own - has no regulatory activity. To identify genes regulated by the $C$. albicans a1, a2, $\alpha 1$ and $\alpha 2$ proteins strains carrying the 16 possible combinations of the four MTL genes described above were compared by transcriptional profiling (UCSF/WI array). All 16 strains were analyzed in the white phase (in SC or YPD media); for the 12 strains competent to switch from white to opaque, also the transcriptional profiles of the opaque forms were analyzed. In all experiments, a reproducible 2-fold change was considered significant.

For the 16 white strains of each MTL configuration, seven genes were found that were reproducibly 
repressed under multiple conditions 2- to 8-fold by a1 and $\alpha 2$ working together in the white phase (in Sac. cerevisiae 20-30 genes are repressed by a1- $\alpha 2$; Galitski et al. 1999). This gene cluster is comprised of CAG1 (homologous to Sac. cerevisiae GPA1), FUS3, FAR1, STE2, YEL003w and two ORFS with no homology to any known genes. These seven genes are controlled by the a1- $\alpha 2$ heterodimer, independent of the white-to-opaque transition. No significant differences between the expression patterns of a and $\alpha$ white cells were observed.

In addition white and opaque versions of strains carrying the 12 MTL configurations permissive for white-opaque switching were compared to a white control strain carrying an intact MTL. Irrespective of the MTL configuration, 237 genes were identified that are up-regulated and 197 genes that are down-regulated in the opaque phase. Transcripts up-regulated in the opaque phase included some likely to be involved in mating in both a and $\alpha$ cells, such as STE4 and FUS3. This set of white and opaque-specific transcripts overlaps with genes identified in a comparison of the white and opaque phases of the genetically different strain WO-1 (Lan et al. 2002).

From the combination of strains investigated two $\alpha$-specific genes were identified. STE3 and $M F \alpha 1$ are highly induced in opaque strains relative to white strains (300- and 1000-fold, respectively), but only in those that carry an intact MTL 1 gene (which are able to mate as $\alpha$-cells). In this data set no a-specific genes were identified in opaquephase a-type cells. However, addition of $\alpha$-factor to cells containing a2 (in the absence of $M T L \alpha$ ) resulted in the induction of 12 genes, including STE6, RAM2, ECE1, HWP1, FIG1, RBT1 and CEK1. These genes of course could also be pheromoneinduced genes rather than a-specific genes (a publication describing a-factor in C. albicans has been just been accepted during finalisation of this article; Dignard et al.2007).

By comparing the mating circuits of Sac. cerevisiae and C. albicans several major differences were identified. One major example of divergence between C. albicans and Sac. cerevisiae in mating type regulation is that $C$. albicans has retained a positive regulator of a-type mating from a common ancestor, while Sac. cerevisiae has lost this regulator. The second major example of divergence is the interposition of an additional layer of transcriptional control in the C. albicans mating type circuit. As described above $C$. albicans a and $\alpha$ cells must undergo a "phenotypic switch" from the white phase to the opaque phase before they are competent to mate (Lockhart et al. 2002; Miller and Johnson 2002). This switch is governed by the mating type locus: two homeodomain proteins $(\mathrm{a} 1, \alpha 2)$ - one from the a locus and one from the $\alpha$ locus - co-operate to repress the switching, thereby assuring that $\mathrm{a} / \mathrm{a}$ and $\alpha / \alpha$, but not a/ $\alpha$ cells, can mate. C. albicans a1 and $\alpha 2$ proteins repress a few genes directly, but control many more indirectly by governing white-opaque switching. This indirect regulation of mating competency by a1$\alpha 2$ in C. albicans constitutes an additional layer of transcriptional regulation, absent in Sac. cerevisiae, which ensures that mating only occurs in specific environments. Recently, a transcriptional regulator, WOR1/TOS9, acting as a master switch regulator, was identified by several groups which is required for establishment of the opaque phase (Huang et al. 2006; Srikantha et al. 2006; Zordan et al. 2006).

\section{Host-Pathogen Interaction}

One of the most interesting events in C. albicans biology is the direct interaction with the host. The switch between commensalisms and pathogen until now could not be studied due to the lack of appropriate models. Experiments focusing on vaginal candidosis have been performed using human volunteers, however, not on a genome-wide platform (Fidel 2007). Mouse models of systemic infection have been used frequently and first attempts to isolate $C$. albicans for genome-wide profiling have been reported (Andes et al. 2005; Fradin et al.2003). Currently, simple model systems mimicking host-pathogen interaction, e.g. C. albicans encountering the host defence, like macrophages and neutrophils or adhering and penetrating into tissue using different reconstituted tissue models derived from cell lines or primary cells, have been used to shed light into C. albicans pathogenesis.

\section{Neutrophils}

Rubin-Bejerano et al. (2003) compared the transcriptional response of Sac. cerevisiae and C. albicans engulfed by neutrophils (UCSF/WI array). In addition the uptake of Sac. cerevisiae in monocytes was investigated. After phagocytosis by neutrophils, both Sac. cerevisiae and C. albicans respond by inducing genes of the methionine and arginine 
pathways. Neither of these pathways is induced upon phagocytosis by monocytes. Both fungi show a similar induction of these pathways when transferred from amino acid-rich medium to amino acid-deficient medium. From these data the authors conclude that the internal phagosome of the neutrophil is an amino acid-deficient environment. In contrast to engulfment by macrophages, Sac. cerevisiae and C. albicans were killed $3 \mathrm{~h}$ after phagocytosis in neutrophils. For Sac. cerevisiae induction of the methionine genes by deprivation was found to be independent of Gcn4, whereas induction of the arginine genes was dependent on Gcn4. In C. albicans GCN4 and PCL5, encoding a Gcn4-stabilizing protein, were induced upon exposure to neutrophils. A stronger oxidative stress response of C. albicans than of Sac. cerevisiae to neutrophils was observed. SOD1, CCP1-1, CTA1-1, CTA 1-2, GPX3-1 and GPX3-2 were induced between 10- and 40-fold. Interestingly, in contrast to monocytes/macrophages, C. albicans is not able to form filaments within neutrophils.

\section{Macrophages}

Lorenz and co-workers (2004) analysed the global transcriptional response of $C$. albicans upon internalization by mouse macrophage line J774A (UCSF/WI array). They could show that phagocytosis stimulates an immediate transcriptional response ( $1 \mathrm{~h}$ time-point). The early pattern is characterized by a dramatic up-regulation of the gluconeogenesis/glyoxylate pathways and downregulation of glycolysis and the genes encoding the translation apparatus. Genes of the TCA cycle which are not part of the glyoxalate cycle are not affected by macrophages. Isocitrate lyase (ICL1) and malate synthase (MLS1) have been found in a previous study to be up-regulated in Sac. cerevisiae and C. albicans (Lorenz and Fink 2001). Consequently, C. albicans mutants lacking ICL1 are markedly less virulent in mice than the wild type. The glyoxalate cycle is also up-regulated in other pathogens like Cryptococcus neoformans, however, deletion of ICL1 does not affect pathogenesis in this organism. In addition to gluconeogenesis and the glyoxylate pathway, $\beta$-oxidation is activated in Candida albicans, indicating a flow of carbon from fatty acids to glucose. Almost all the genes encoding for ribosomal proteins as well as many genes required for the translation apparatus are strongly down-regulated. Mitochondrial translation, how- ever, is reported to be unaffected by phagocytosis (both the glyoxalate cycle and $\beta$-oxidation require mitochondria). A specific nonmetabolic response distinct from filamentation embedded in the early pattern that responds to stresses presented by macrophage contact was also identified, including machinery for DNA damage repair, oxidative stress responses, peptide uptake systems and arginine biosynthesis. Filamentation-specific genes have not been identified since the control cultures in RPMI + serum induced hyphae at the same rate as in the presence of macrophages. Thus macrophages seem to not specific induce a filamentation response. This early transcription profile switches to a later profile which is highly similar to the profile of the cells grown without macrophages. This basically reflects the observation that $C$. albicans has escaped form the macrophages and grows now in tissue culture medium (RPMI + serum), like the control culture. The non-filamentous cph1 efg1 mutant (Lo et al. 1997), which is internalized but cannot escape, remains frozen in the early pattern. Interestingly, the avirulent cph1efg1 mutant is not killed within the macrophages (J774A cell line), it actually is able to double within the $6 \mathrm{~h}$ timecourse experiment conducted, indicating that the macrophages used in this study do not play a role in the host's defence mechanism against C. albicans (J774A is able to kill Sac. cerevisiae).

In order to confirm that the metabolic reprogramming after phagocytosis is due to lack of nutrients, similar starvation conditions were mimicked in vitro by omitting $\mathrm{C}$-, or $\mathrm{N}$-sources or both in synthetic growth media. From these data it was concluded that the similarities between phagocytosed cells and starvation were only to cells deprived of a carbon source. Nitrogen-depleted cells show a significantly different pattern of gene expression, with little to no overlap with ingested cells. A cluster of 227 genes specific for response to macrophages could be identified from the data. Only one metabolic pathway specific to macrophage phagocytosis was found by comparison with the in vitro starvation conditions. This was the arginine biosynthetic pathway with all but one of the ten genes strongly up-regulated. The reason for this is unknown. In addition a set of 117 genes including transporters required mostly for $\mathrm{N}$-source uptake and vacuolar proteases have been identified. Only a few genes responsible for oxidative stress defence (including YHB1, GPX3 and CCP1) or metal homeostasis (including FRE3, FRE7 and CTR1 required 
for iron homeostasis) and DNA repair were mentioned as macrophage-specific.

Most interestingly the early response described in this study is basically absent in the Sac. cerevisiae. In contrast to C. albicans where 545 genes respond to internalisation, only 53 respond in Sac. cerevisiae (Lorenz and Fink 2001), underscoring the pathogen/non-pathogen differences and revealing a highly co-ordinated system in C. albicans for immune evasion.

\section{Blood}

In two studies, Fradin et al. $(2003,2005)$ focused on the transcriptional response of $C$. albicans to human blood and the individual components of blood (Eurogentec array). This environment is interesting because survival in blood and escape from blood vessels into tissues are essential steps for the pathogen to cause systemic infections. Whole blood induced genes that are involved in general and oxidative stress response, the glyoxylate cycle and protein biosynthesis. Subsets of these genes were also detected from $C$. albicans isolated after tailvein infection of mice (Fradin et al. 2003). To determine how different blood components affect the C. albicans gene expression profile, the blood was separated into five fractions: enriched in erythrocytes (EC), polymorphonuclear leukocytes (PMN) and mononuclear leukocytes (MNC) or depleted of neutrophils or all blood cells (i.e. plasma; Fradin et al. 2005). C. albicans exposed to PMNs rapidly loses viability, whereas exposure to MNCs, plasma or erythrocytes has no effect on its viability. These fractions were inoculated for $30 \mathrm{~min}$ with $C$. albicans $\left(5 \times 10^{6}\right.$ cells $\left./ \mathrm{ml}\right)$ and compared with C. albicans cells incubated with erythrocytes. Of the ORFs represented on the microarray, $25 \%$ (1518 genes) were shown to be modulated (1.5-fold changes) under at least one of the five conditions tested. These studies revealed that the transcript profiles of $C$. albicans exposed to EC, MNC and plasma are highly similar, whereas the transcriptional profiles of PMN and whole blood are similar to each other, indicating that PMN, consisting (to 90\%) of neutrophils, are the cellular component responsible for the strong reaction of $C$. albicans to blood. This was confirmed by depleting whole blood from neutrophils using an antibody directed against CD15 (present on neutrophils and eosinophils). Upon exposure to EC, MNC, plasma or blood lacking neutrophils $C$. albicans rapidly switched to filamentous growth. The presence of neutrophils blocked hyphal development and resulted in growth arrest (see also
Rubin-Bejerano et al. 2003). Consequently, most of the known hyphae-specific genes, such as SAP4$S A P 6, H Y R 1, E C E 1$ and $A L S 3$, were repressed in the $\mathrm{PMN}$ fractions. Growth inhibition is reflected in the dramatic transcript reduction of genes involved in protein synthesis, including genes coding for ribosomal proteins (RPS10, RPL12), translation elongation factors (EFB1, EFT3), or translation initiators (GCD7, GCN3). This is paralleled by the induction of genes required for the response to nitrogen and carbohydrate starvation, like genes involved in the arginine, leucine, lysine and methionine biosynthesis pathways, GCN4 (transcriptional activator of amino acid biosynthesis), several genes encoding amino acid transporters involved in general nitrogen metabolism and the ammonium permeases Mep2 and Mep3. In addition genes encoding the vacuolar proteases Prb1, Prb2, Apr1, Prc1/Cpy1 and Prc2 were also expressed at higher levels in the presence of neutrophils. The availability of carbohydrates to C. albicans also seemed to be reduced in the presence of neutrophils, as the genes encoding the key enzymes of the glyoxylate cycle (MLS1,ICL1, ACS1) were strongly up-regulated (not reported by Rubin-Bejerano et al. 2003).Thus, growth inhibition by PMNs might be due to nutrient starvation. Fungal cells incubated with MNC also expressed to higher level genes involved in nitrogen metabolism, the glyoxylate cycle and the antioxidative response. However, the expression of these genes was reported to be significantly lower than for $C$. albicans cells exposed to neutrophils (see also Lorenz et al. 2004).

C. albicans genes encoding the cytoplasmic and the surface superoxide dismutase (SOD1, SOD5), the catalase (CTA1), the glutathione peroxidase/ glutathione reductase complex and the thioredoxin peroxidase/thioredoxin reductase complex were up-regulated strongly in the presence of neutrophils. Three out of the 18 antioxidant genes identified in this study were also found to be induced by $C$. albicans in response to neutrophils by RubinBejerano et al. (2003): SOD1, CTA1 and GPX3. In addition, several of these genes (including TTR1, $T R X 1, C T A 1, C A P 1)$ were identified by Enjalbert et al. (2003) who investigated the transcriptional profile of C. albicans exposed to oxidative stress.

Most interestingly, only $38 \%$ of all fungal cells were phagocytosed by and $57.5 \%$ attached to neutrophils in the PMN fraction, suggesting that the observed effects resulted from both intra- and extracellular activities of neutrophils. Most of these cells showed SOD5 expression (as monitored by GFP fluorescence) and were arrested in the yeast form. Studies by Urban et al. (2006) indeed showed 
that neutophils are able to act not only by phagocytosis. The supernatant of PMNs does not result in inhibition of hyphal growth, suggesting that contact between $C$. albicans and neutrophils is crucial for inhibition of the yeast to hyphal transition.

\section{Epithelial Surfaces}

Adhesion to mammalian epithelia is one of the prerequisites for colonisation and invasion of C. albicans in the host. C. albicans is able to adhere to a plethora of different host niches consisting of different cell types providing individual micro-environments for colonization (Fig. 9.2).

Sandovsky-Losica investigated the transcriptional response of $C$. albicans to HEp2 epithelial cells (Sandovsky-Losica et al.2006). Changes in gene transcription of $C$. albicans were determined following infection of HEp2 cells compared to control cultures grown in the absence of HEp2 cells. Among the approximately 300 genes which were identified as differentially regulated for at least 2 -fold following
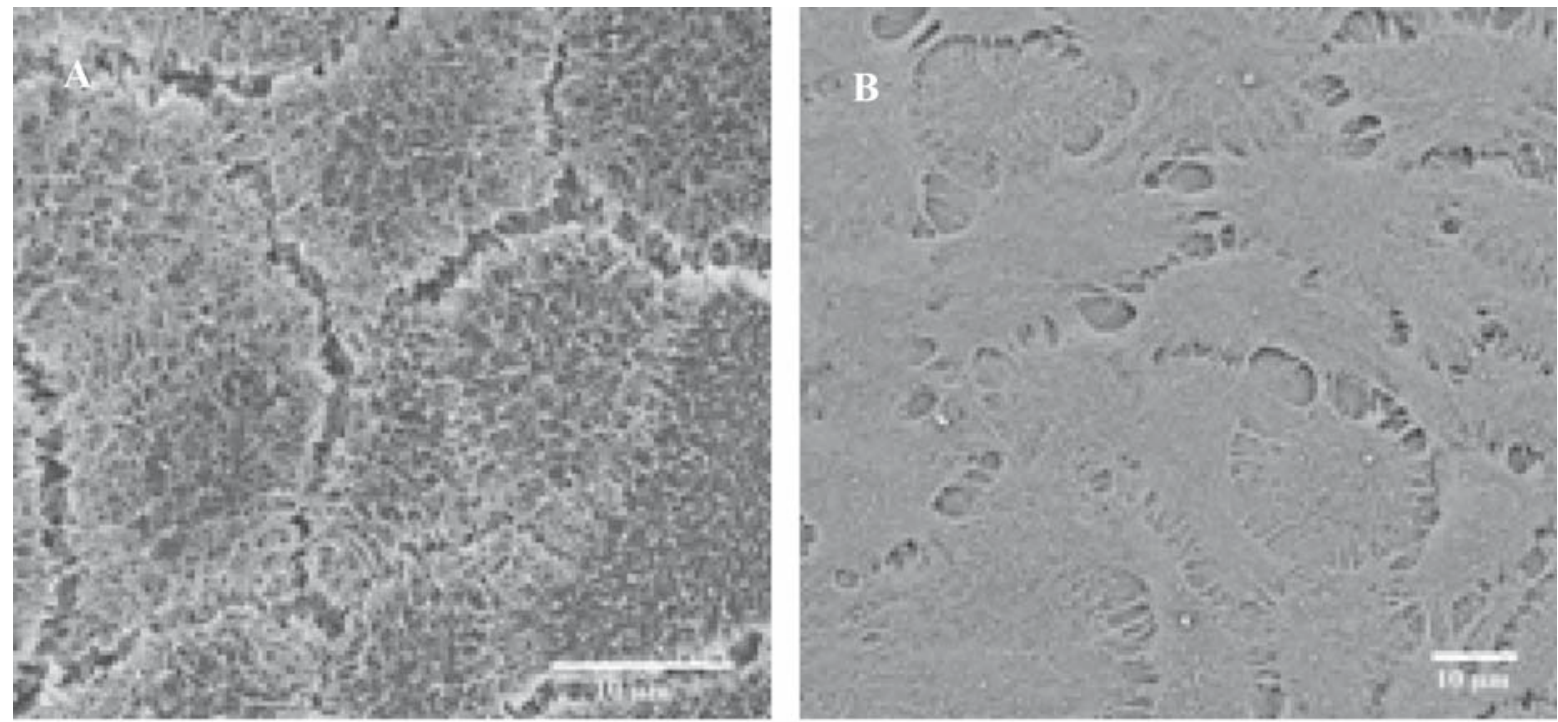

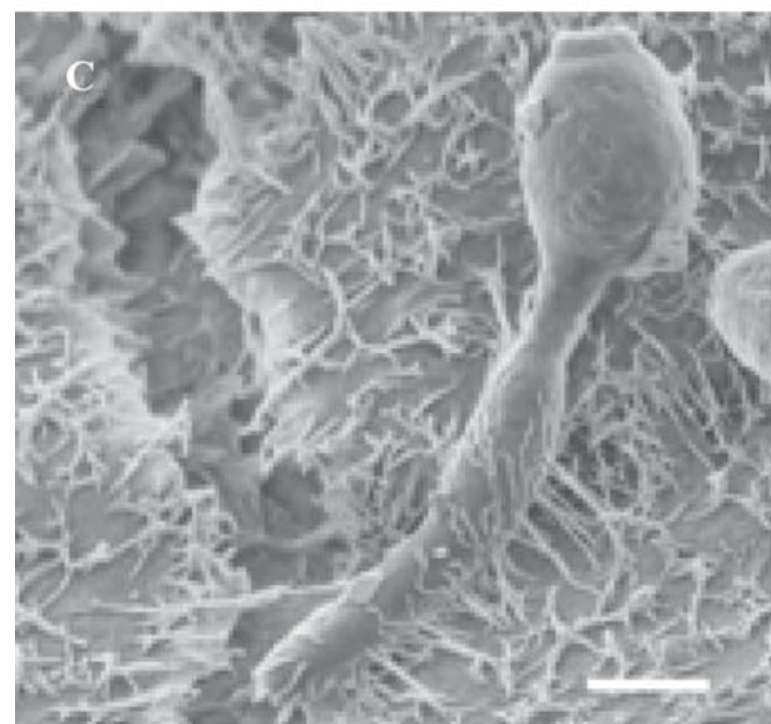

Fig. 9.2. Scanning electron microscopy of in vitro-infected epithelia. The human colorectal adenocarcinoma cell line Caco-2 (A) and the human epidermoid cell line A-431(B) are used as model systems for early events of adhesion and invasion (Sohn 2006). C. albicans was incubated for

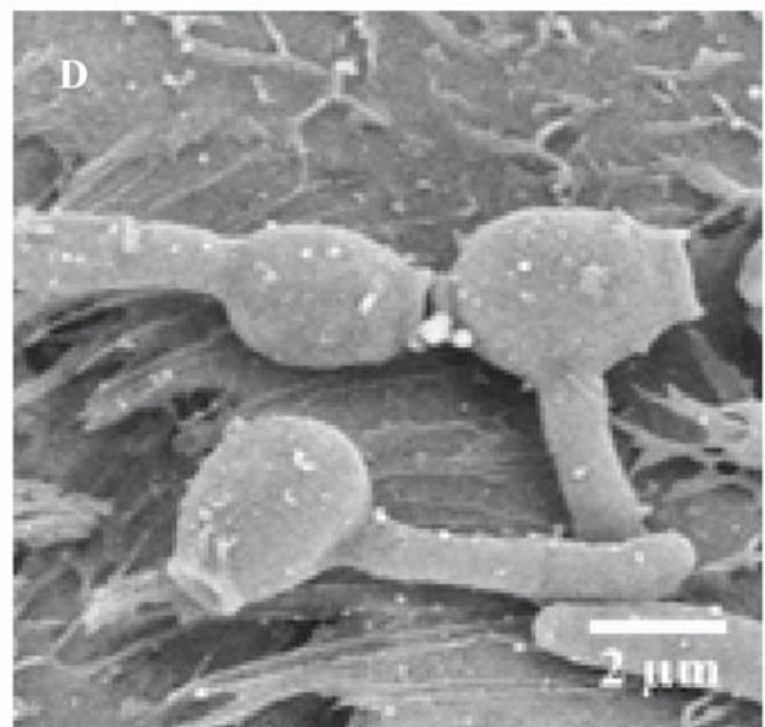

2h on Caco-2 (C) or A-431 cells (D). The different surface structure of each epithelia influences the interaction between C. albicans and the epithelial surface (e.g. see interaction between $C$. albicans and microvilli-like structures on the Caco- 2 cells in (C)) 
$3 \mathrm{~h}$ incubation with HEp2 ALS2 and ALS5 were identified as up-regulated. Both genes encode proteins that provide an adherence function for C. albicans.

To study the early response of $C$. albicans adhering to different surfaces on the transcriptional level Sohn et al. (2006) have established an in vitro adhesion assay exploiting confluent monolayers of the human colorectal carcinoma cell line Caco-2 or epidermoid vulvo-vaginal A431 cells. C. albicans very efficiently adheres to these epithelia growing as hyphae within 1-3h. Transcriptional profiles (IGB array) of C. albicans adhering to Caco-2 or to A-431 cells, although very similar, still significantly differ from those of Candida cells adhering to plastic surfaces or grown in suspension. Correspondingly from the 260 genes differentially regulated, several cell surface genes were identified, including PRA1, PGA23, PGA7 and $H W P 1$, showing either a cell-type or adhesion-dependent induction of transcription. Especially the kinetics of hyphal induction were much faster when C. albicans was grown on a surface, plastic or epithelia, as shown morphologically and molecularly by a more rapid and stronger induction of hyphae-specific genes like HWP1. Obviously, C. albicans is able to respond specifically to very subtle differences in the environment during adhesion to various growth substrates.

\section{E. Biofilm Formation}

Biofilm formation by $C$. albicans is a complex process with significant consequences for human health. It contributes to implanted medical deviceassociated infections and results in resistance, especially to azoles. Initial studies of C. albicans biofilm visualized yeast cells, pseudohyphae and hyphae embedded in an extracellular matrix using scanning electron microscopy. This and subsequent studies (Hawser and Douglas 1994; Baillie and Douglas 1999; Chandra et al. 2001; Ramage et al. 2001; Douglas 2003) showed that biofilm formation in vitro can be broken down into three basic stages: (a) attachment and colonization of yeast cells to a surface, (b) growth and proliferation of yeast cells to allow the formation of a basal layer of anchoring cells and (c) growth of pseudohyphae and extensive hyphae together with the production of extracellular matrix material. For recent reviews, see Nett and Andes (2006) and Nobile and Mitchell (2006). Several models for biofilm formation have been developed and transcriptional profiling has been performed on early and late stages of biofilm formation as well as on the impact of farnesol on biofilm formation (Cao et al. 2005; Garcia-Sanchez et al. 2004; Murillo et al. 2005).

Garcia-Sanchez and co-workers (2004) compared biofilm and planktonic cultures produced under different conditions of nutrient flow, aerobiosis or glucose concentration by overall gene expression correlation (partial macroarray containing 2002 ORFs). Correlation was much higher between biofilms than planktonic populations irrespective of the growth conditions, indicating that biofilm populations formed in different environments display very similar and specific transcript profiles. The authors found over-representation of amino acid biosynthesis genes in biofilms. Consequently, Gcn4p, a regulator of amino acid metabolism, was shown to be required for normal biofilm growth. Hyphal formation has been thought to be required for biofilm formation; however, a biofilmlike structure formed by the efg1cph1 mutant strain locked in the yeast/pseudohyphal growth forms lacks hyphae entirely (Garcia-Sanchez et al.2004). Still the majority of genes discovered to be involved in biofilm formation are also required for hyphal formation indicating the importance of hyphae for biofilm formation (Richard et al.2005). Consequently, farnesol, a quorum-sensing molecule which inhibits hyphal morphogenesis results in inhibition of biofilm formation (Ramage et al. $2002 \mathrm{~b}$ ). Addition of farnesol alters the expression of 274 genes in a biofilm, including a significant number of hyphal-associated gene expression in biofilms (Cao et al. 2005). This again suggested that hyphal formation is a key factor for biofilm formation.

Cell surface contact is a key requirement for biofilm formation. At just $30 \mathrm{~min}$ after C. albicans yeast cells contact a polystyrene surface, a gene expression programme is initiated that is distinct from that of planktonic cells grown under otherwise similar conditions (Murillo et al. 2005; Sohn et al.2006). This includes the development of drug resistance. Mateus et al. (2004) have observed that $C D R 1$ and MDR1 promoter activities increase within 15-30 min after the adherence of cells to a glass slide, using promoter fusions to a GFP reporter gene (not observed in profiling studies by Murillo et al. 2005). The importance of $C D R 1 / 2$ and MDR1 in resistance of a biofilm to FCZ was confirmed by mutational studies (Mateus et al. 
2004). Interestingly at later time-points during biofilm formation the efflux pumps have no further effect on drug resistance in a biofilm (Mukherjee et al.2003), suggesting additional mechanisms for resistance.

Noteworthy is the up-regulation of several methionine and cysteine biosynthetic genes, whose transcript levels remain elevated for many hours (Garcia-Sanchez et al. 2004; Murillo et al. 2005). The methionine and cysteine gene set is up-regulated during biofilm development under diverse conditions, even in the biofilm formed by the efg $1 c p h 1$ mutant that lacks hyphae (Garcia-Sanchez et al. 2004). Although the functional role of methionine and cysteine biosynthetic genes in biofilm development has yet to be determined, the rapid up-regulation of these and other genes suggests that C. albicans may sense cell surface contact or perhaps the presence of neighbouring cells.

One of the key regulators required specifically for biofilm formation (and not for hyphal development in general) is Bcrl, which in turn is regulated by TEC1 (Nobile and Mitchell 2005). Comparison of transcriptional profiling (Operon array) of a $b r c 1$ mutant with its complemented strain $(\Delta b r c 1$ $+p B R C 1$; in suspension culture, Spider medium, $37^{\circ} \mathrm{C}$ ) revealed among the 22 most severely altered genes, 11 specifying cell surface- or cell wallmodifiying proteins, including $H Y R 1, E C E 1, R B T 5$, ECM331, HWP1, ALS1, ALS3 and ALS9. Using the brcl mutant strain made it possible to separate the circuits required for hyphal morphogenesis and biofilm formation. The failure of the $b r c 1$ mutant to create a biofilm indicates that the hyphal surface proteins are required for biofilm formation. Recent mutational approaches focusing on $A L S 1$, ALS3, HWP1 and ECE1 could confirm their importance for biofilm formation (Nobile et al. 2006a, b; Zhao et al. 2006).

\section{Conclusions}

Transcriptomics has been used to create a comprehensive picture of changes in gene expression of C. albicans during host-pathogen interaction, stress response or other environmental challenges. Individual genes could be identified as central components in several pathways, making them especially important for understanding pathogenesis.
In addition these studies also reveal that besides individual virulence factors, the appropriate regulation of metabolic pathways are essential to adapt to the host and survive in it. Indeed the expression of virulence factors and metabolic pathways are tightly coupled, e.g. via Efg1. This manifests the complexity and interaction between different pathways reflecting a dense biological network rather than linear pathways.

This review also shows that similar experiments using microarrays based on the same genome sequence might result in only very limited overlap with regard to the genes found to be differentially regulated. One of the reasons certainly is that apparently slightly different conditions in the experimental setup might lead to significant changes in the transcriptome. Furthermore, significant differences both in early and late established arrays, the definition of ORFs and the design of various distinct oligo sets or PCR-products for detection of the individual transcripts result in differences in the detection of the individual transcripts. However, verification of the quality of transcriptome data as well as their analysis is crucial for their interpretation. Especially, selecting the "good" signals from the "bad" in a complex series of experiments, including all necessary controls, is still a field with a lot of opportunities for advancement. Therefore, results from transcriptome studies should in general not be considered as complete genome-wide datasets but rather a dataset of significantly expressed genes which are modulated under the specific conditions applied. Although there are differences in the present studies, the general concusion drawn is usually identical. This reflects the huge benefits which can be gained from this technology.

The availability of the genome sequence was key for the realisation of genome-wide arrays as tools to perform these studies. The increasing wealth of genomic sequences from both pathogenic and non-pathogenic fungi will lead to increasing numbers of genome-wide transcriptional data from multiple species. As a result, we will be able to compare pathogenic fungi not only on the genome level, but on a transcriptional level and thereby further advance our understanding of pathogenesis. This will ultimately contribute to the better understanding of the mechanisms of infection and thus foster the development of new diagnostics, therapeutics and vaccines. 
Acknowledgments. I would like to thank Rosa HernadezBarbado, Kai Sohn and Martin Zavrel for suggestions and critical reading of the manuscript. This chapter has been made possible by the DFG (Ru608/4) and the EU (Marie Curie Research Training Network, CanTrain).

\section{References}

Agarwal AK, Rogers PD, Baerson SR, Jacob MR, Barker KS, Cleary JD, Walker LA, Nagle DG, Clark AM (2003) Genome-wide expression profiling of the response to polyene, pyrimidine, azole, and echinocandin antifungal agents in Saccharomyces cerevisiae. J Biol Chem 278:34998-35015

Alarco AM, Raymond M (1999) The bZip transcription factor Cap1p is involved in multidrug resistance and oxidative stress response in Candida albicans. J Bacteriol 181:700-708

Andes D, Ogtrop M van (1999) Characterization and quantitation of the pharmacodynamics of fluconazole in a neutropenic murine disseminated candidiasis infection model. Antimicrob Agents Chemother 43:2116-2120

Andes D, Lepak A, Pitula A, Marchillo K, Clark J (2005) A simple approach for estimating gene expression in Candida albicans directly from a systemic infection site. J Infect Dis 192:893-900

Andrade RV, Da Silva SP, Torres FA, Pocas-Fonseca MJ, Silva-Pereira I, Maranhao AQ, Campos EG, Moraes LM, Jesuino RS, Pereira M et al (2005) Overview and perspectives the transcriptome of Paracoccidioides brasiliensis. Rev Iberoam Micol 22:203-212

Arnaud MB, Costanzo MC, Skrzypek MS, Binkley G, Lane C, Miyasato SR, Sherlock G (2005) The Candida genome database (CGD), a community resource for Candida albicans gene and protein information. Nucleic Acids Res 33:D358-D363

Arnaud MB, Costanzo MC, Skrzypek MS, Shah P, Binkley G, Lane C, Miyasato SR, Sherlock G (2007) Sequence resources at the Candida genome database. Nucleic Acids Res 35:D452-D456

Bammert GF, Fostel JM (2000) Genome-wide expression patterns in Saccharomyces cerevisiae: comparison of drug treatments and genetic alterations affecting biosynthesis of ergosterol. Antimicrob Agents Chemother 44:1255-1265

Barbulovic-Nad I, Lucente M, Sun Y, Zhang M, Wheeler AR, Bussmann M (2006) Bio-microarray fabrication techniques - a review. Crit Rev Biotechnol 26:237-259

Barker KS, Crisp S, Wiederhold N, Lewis RE, Bareither B, Eckstein J, Barbuch R, Bard M, Rogers PD (2004) Genome-wide expression profiling reveals genes associated with amphotericin B and fluconazole resistance in experimentally induced antifungal resistant isolates of Candida albicans. J Antimicrob Chemother 54:376-385

Bennett RJ, Uhl MA, Miller MG, Johnson AD (2003) Identification and characterization of a Candida albicans mating pheromone. Mol Cell Biol 23:8189-8201

Bensen ES, Filler SG, Berman J (2002) A forkhead transcription factor is important for true hyphal as well as yeast morphogenesis in Candida albicans. Eukaryot Cell 1:787-798

Bensen ES, Martin SJ, Li M, Berman J, Davis DA (2004) Transcriptional profiling in Candida albicans reveals new adaptive responses to extracellular $\mathrm{pH}$ and functions for Rim101p. Mol Microbiol 54:1335-1351

Berman J, Sudbery PE (2002) Candida albicans: a molecular revolution built on lessons from budding yeast. Nat Rev Genet 3:918-930

Bockmuhl DP, Ernst JF (2001) A potential phosphorylation site for an A-type kinase in the Efg1 regulator protein contributes to hyphal morphogenesis of Candida albicans. Genetics 157:1523-1530

Braun BR, Johnson AD (1997) Control of filament formation in Candida albicans by the transcriptional repressor TUP1 [see comments]. Science 277:105-109

Braun BR, Kadosh D, Johnson AD (2001) NRG1, a repressor of filamentous growth in C.albicans, is down-regulated during filament induction. EMBO J 20:4753-4761

Braun BR, Het Hoog M van, d'Enfert C, Martchenko M, Dungan J, Kuo A, Inglis DO, Uhl MA, Hogues H, Berriman $\mathrm{M}$ et al (2005) A human-curated annotation of the Candida albicans genome. PLoS Genet 1:36-57

Calderone RA (2002) Candida and candidiasis. ASM Press, Washington, D.C.

Cao F, Lane S, Raniga PP, Lu Y, Zhou Z, Ramon K, Chen J, Liu H (2006) The Flo8 transcription factor is essential for hyphal development and virulence in Candida albicans. Mol Biol Cell 17:295-307

Cao YY, Cao YB, Xu Z, Ying K, Li Y, Xie Y, Zhu ZY, Chen WS, Jiang YY (2005) cDNA microarray analysis of differential gene expression in Candida albicans biofilm exposed to farnesol. Antimicrob Agents Chemother 49:584-589

Carter GW, Rupp S, Fink GR, Galitski T (2006) Disentangling information flow in the Ras-cAMP signaling network. Genome Res 16:520-526

Casadevall A, Pirofski LA (2003) The damage-response framework of microbial pathogenesis. Nat Rev Microbiol 1:17-24

Chauhan N, Inglis D, Roman E, Pla J, Li D, Calera JA, Calderone R (2003) Candida albicans response regulator gene SSK1 regulates a subset of genes whose functions are associated with cell wall biosynthesis and adaptation to oxidative stress. Eukaryot Cell 2:1018-1024

Cleaveland S, Laurenson MK, Taylor LH (2001) Diseases of humans and their domestic mammals: pathogen characteristics, host range and the risk of emergence. Philos Trans R Soc Lond B Biol Sci 356:991-999

Costanzo MC, Arnaud MB, Skrzypek MS, Binkley G, Lane C, Miyasato SR, Sherlock G (2006) The Candida genome database: facilitating research on Candida albicans molecular biology. FEMS Yeast Res 6:671-684

Coste AT, Karababa M, Ischer F, Bille J, Sanglard D (2004) TAC1, transcriptional activator of CDR genes, is a new transcription factor involved in the regulation of Candida albicans ABC transporters CDR1 and CDR2. Eukaryot Cell 3:1639-1652

Cowen LE, Sanglard D, Calabrese D, Sirjusingh C, Anderson JB, Kohn LM (2000) Evolution of drug resistance in experimental populations of Candida albicans. J Bacteriol 182:1515-1522 
Cowen LE, Nantel A, Whiteway MS, Thomas DY, Tessier DC, Kohn LM, Anderson JB (2002) Population genomics of drug resistance in Candida albicans. Proc Natl Acad Sci USA 99:9284-9289

Cramer KL, Gerrald QD, Nichols CB, Price MS, Alspaugh JA (2006) Transcription factor Nrg1 mediates capsule formation, stress response, and pathogenesis in Cryptococcus neoformans. Eukaryot Cell 5:1147-1156

Davis D, Wilson RB, Mitchell AP (2000) RIM101-dependent and-independent pathways govern $\mathrm{pH}$ responses in Candida albicans. Mol Cell Biol 20:971-978

De Backer MD, Ilyina T, Ma XJ, Vandoninck S, Luyten WH, Vanden Bossche H (2001) Genomic profiling of the response of Candida albicans to itraconazole treatment using a DNA microarray. Antimicrob Agents Chemother 45:1660-1670

d'Enfert C, Goyard S, Rodriguez-Arnaveilhe S, Frangeul L, Jones L, Tekaia F, Bader O, Albrecht A, Castillo L, Dominguez A et al (2005) CandidaDB: a genome database for Candida albicans pathogenomics. Nucleic Acids Res 33:D353-D357

DeRisi JL, Iyer VR, Brown PO (1997) Exploring the metabolic and genetic control of gene expression on a genomic scale. Science 278:680-686

Dieterich C, Schandar M, Noll M, Johannes FJ, Brunner H, Graeve T, Rupp S (2002) In vitro reconstructed human epithelia reveal contributions of Candida albicans EFG1 and CPH1 to adhesion and invasion. Microbiology 148:497-506

Dignard D, El-Naggar AL, Logue ME, Butler G, Whiteway M (2007) Identification and characterization of MFA1; the gene encoding Candida albicans a-factor pheromone. Eukaryot Cell (in press)

Doedt T, Krishnamurthy S, Bockmuhl DP, Tebarth B, Stempel C, Russell CL, Brown AJ, Ernst JF (2004) APSES proteins regulate morphogenesis and metabolism in Candida albicans. Mol Biol Cell 15:3167-3180

Du C, Calderone R, Richert J, Li D (2005) Deletion of the SSK1 response regulator gene in Candida albicans contributes to enhanced killing by human polymorphonuclear neutrophils. Infect Immun 73:865-871

Dujon B, Sherman D, Fischer G, Durrens P, Casaregola S, Lafontaine I, De Montigny J, Marck C, Neuveglise C, Talla E et al (2004) Genome evolution in yeasts. Nature 430:35-44

Eisenstein M (2006) Microarrays: quality control. Nature 442:1067-1070

El Barkani A, Kurzai O, Fonzi WA, Ramon A, Porta A, Frosch M, Muhlschlegel FA (2000) Dominant active alleles of RIM101 (PRR2) bypass the $\mathrm{pH}$ restriction on filamentation of Candida albicans. Mol Cell Biol 20:4635-4647

Enjalbert B, Nantel A, Whiteway M (2003) Stress-induced gene expression in Candida albicans: absence of a general stress response. Mol Biol Cell 14:1460-1467

Enjalbert B, Smith DA, Cornell MJ,Alam I, Nicholls S, Brown AJ, Quinn J (2006) Role of the Hog1 stress-activated protein kinase in the global transcriptional response to stress in the fungal pathogen Candida albicans. Mol Biol Cell 17:1018-1032

Fang FC (2004) Antimicrobial reactive oxygen and nitrogen species: concepts and controversies. Nat Rev Microbiol 2: 820-832
Fellenberg K, Busold CH, Witt O, Bauer A, Beckmann B, Hauser NC, Frohme M, Winter S, Dippon J, Hoheisel JD (2006) Systematic interpretation of microarray data using experiment annotations. BMC Genomics 7:319

Fidel PL Jr (2007) History and update on host defense against vaginal candidiasis. Am J Reprod Immunol 57:2-12

Fonzi WA, Irwin MY (1993) Isogenic strain construction and gene mapping in Candida albicans. Genetics 134:717-728

Fradin C, Kretschmar M, Nichterlein T, Gaillardin C, d'Enfert C, Hube B (2003) Stage-specific gene expression of Candida albicans in human blood. Mol Microbiol 47:1523-1543

Fradin C, De Groot P, MacCallum D, Schaller M, Klis F, Odds FC, Hube B (2005) Granulocytes govern the transcriptional response, morphology and proliferation of Candida albicans in human blood. Mol Microbiol 56:397-415

Galagan JE, Henn MR, Ma LJ, Cuomo CA, Birren B (2005) Genomics of the fungal kingdom: insights into eukaryotic biology. Genome Res 15:1620-1631

Galitski T, Saldanha AJ, Styles CA, Lander ES, Fink GR (1999) Ploidy regulation of gene expression. Science 285:251-254

Garcia-Sanchez S, Aubert S, Iraqui I, Janbon G, Ghigo JM, d'Enfert C (2004) Candida albicans biofilms: a developmental state associated with specific and stable gene expression patterns. Eukaryot Cell 3:536-545

Garcia-Sanchez S, Mavor AL, Russell CL, Argimon S, Dennison P, Enjalbert B, Brown AJ (2005) Global roles of Ssn6 in Tup1- and Nrg1-dependent gene regulation in the fungal pathogen, Candida albicans. Mol Biol Cell 16:2913-2925

Gebhart D, Bahrami AK, Sil A (2006) Identification of a copper-inducible promoter for use in ectopic expression in the fungal pathogen Histoplasma capsulatum. Eukaryot Cell 5:935-944

Gupta V, Kohli A, Krishnamurthy S, Puri N, Aalamgeer SA, Panwar S, Prasad R (1998) Identification of polymorphic mutant alleles of CaMDR1, a major facilitator of Candida albicans which confers multidrug resistance, and its in vitro transcriptional activation. Curr Genet 34:192-199

Harcus D, Nantel A, Marcil A, Rigby T, Whiteway M (2004) Transcription profiling of cyclic AMP signaling in Candida albicans. Mol Biol Cell 15:4490-4499

Hauser NC, Vingron M, Scheideler M, Krems B, Hellmuth K, Entian KD, Hoheisel JD (1998) Transcriptional profiling on all open reading frames of Saccharomyces cerevisiae. Yeast 14:1209-1221

Herskowitz I (1989) A regulatory hierarchy for cell specialization in yeast. Nature 342:749-757

Hromatka BS, Noble SM, Johnson AD (2005) Transcriptional response of Candida albicans to nitric oxide and the role of the YHB1 gene in nitrosative stress and virulence. Mol Biol Cell 16:4814-4826

Huang G, Wang H, Chou S, Nie X, Chen J, Liu H (2006) Bistable expression of WOR1, a master regulator of whiteopaque switching in Candida albicans. Proc Natl Acad Sci USA 103:12813-12818 
Hwang CS, Oh JH, Huh WK, Yim HS, Kang SO (2003a) Ssn6, an important factor of morphological conversion and virulence in Candida albicans. Mol Microbiol 47:1029-1043

Hwang L, Hocking-Murray D, Bahrami AK, Andersson M, Rine J,Sil A (2003b) Identifying phase-specific genes in the fungal pathogen Histoplasma capsulatum using a genomic shotgun microarray. Mol Biol Cell 14:2314-2326

Ihmels J, Bergmann S, Berman J, Barkai N (2005) Comparative gene expression analysis by differential clustering approach: application to the Candida albicans transcription program. PLoS Genet 1:e39

Johannesson H, Kasuga T, Schaller RA, Good B, Gardner MJ, Townsend JP, Cole GT, Taylor JW (2006) Phasespecific gene expression underlying morphological adaptations of the dimorphic human pathogenic fungus, Coccidioides posadasii. Fungal Genet Biol 43:545-559

Jones T, Federspiel NA, Chibana H, Dungan J, Kalman S, Magee BB, Newport G, Thorstenson YR, Agabian N, Magee PT et al (2004) The diploid genome sequence of Candida albicans. Proc Natl Acad Sci USA 101:73297334

Kadosh D, Johnson AD (2005) Induction of the Candida albicans filamentous growth program by relief of transcriptional repression: a genome-wide analysis. Mol Biol Cell 16:2903-2912

Karababa M, Coste AT, Rognon B, Bille J, Sanglard D (2004) Comparison of gene expression profiles of Candida albicans azole-resistant clinical isolates and laboratory strains exposed to drugs inducing multidrug transporters. Antimicrob Agents Chemother 48:30643079

Kelly SL, Lamb DC, Kelly DE, Manning NJ, Loeffler J, Hebart H, Schumacher U, Einsele H (1997) Resistance to fluconazole and cross-resistance to amphotericin B in Candida albicans from AIDS patients caused by defective sterol delta5,6-desaturation. FEBS Lett 400:80-82

Kraus PR, Boily MJ, Giles SS, Stajich JE, Allen A, Cox GM, Dietrich FS, Perfect JR, Heitman J (2004) Identification of Cryptococcus neoformans temperature-regulated genes with a genomic-DNA microarray. Eukaryot Cell 3:1249-1260

Lamb TM, Mitchell AP (2003) The transcription factor Rim101p governs ion tolerance and cell differentiation by direct repression of the regulatory genes NRG1 and SMP1 in Saccharomyces cerevisiae. Mol Cell Biol 23:677-686

Lan CY, Newport G, Murillo LA, Jones T, Scherer S, Davis RW, Agabian N (2002) Metabolic specialization associated with phenotypic switching in Candida albicans. Proc Natl Acad Sci USA 99:14907-14912

Lan CY, Rodarte G, Murillo LA, Jones T, Davis RW, Dungan J, Newport G, Agabian N (2004) Regulatory networks affected by iron availability in Candida albicans. Mol Microbiol 53:1451-1469

Lander ES, Linton LM, Birren B, Nusbaum C, Zody MC, Baldwin J, Devon K, Dewar K, Doyle M, FitzHugh $W$ et al (2001) Initial sequencing and analysis of the human genome. Nature 409:860-921

Lane S, Birse C, Zhou S, Matson R, Liu H (2001) DNA array studies demonstrate convergent regulation of virulence factors by Cph1, Cph2, and Efg1 in Candida albicans. J Biol Chem 276:48988-48996

Lee CM, Nantel A, Jiang L, Whiteway M, Shen SH (2004) The serine/threonine protein phosphatase SIT4 modulates yeast-to-hypha morphogenesis and virulence in Candida albicans. Mol Microbiol 51:691-709

Lee RE, Liu TT, Barker KS, Rogers PD (2005) Genome-wide expression profiling of the response to ciclopirox olamine in Candida albicans. J Antimicrob Chemother 55:655-662

Lepak A, Nett J, Lincoln L, Marchillo K, Andes D (2006) Time course of microbiologic outcome and gene expression in Candida albicans during and following in vitro and in vivo exposure to fluconazole. Antimicrob Agents Chemother 50:1311-1319

Leuker CE, Sonneborn A, Delbruck S, Ernst JF (1997) Sequence and promoter regulation of the PCK1 gene encoding phosphoenolpyruvate carboxykinase of the fungal pathogen Candida albicans. Gene 192:235-240

Lewis JG, Learmonth RP, Watson K (1995) Induction of heat, freezing and salt tolerance by heat and salt shock in Saccharomyces cerevisiae. Microbiology 141:687-694

Liu H (2001) Transcriptional control of dimorphism in Candida albicans. Curr Opin Microbiol 4:728-735

Liu H (2002) Co-regulation of pathogenesis with dimorphism and phenotypic switching in Candida albicans, a commensal and a pathogen. Int J Med Microbiol 292:299-311

Liu TT, Lee RE, Barker KS, Wei L, Homayouni R, Rogers PD (2005) Genome-wide expression profiling of the response to azole, polyene, echinocandin, and pyrimidine antifungal agents in Candida albicans. Antimicrob Agents Chemother 49:2226-2236

Lo HJ, Kohler JR, Di Domenico B, Loebenberg D, Cacciapuoti A, Fink GR (1997) Nonfilamentous C. albicans mutants are avirulent. Cell 90:939-949

Lockhart SR, Pujol C, Daniels KJ, Miller MG, Johnson AD, Pfaller MA, Soll DR (2002) In Candida albicans, whiteopaque switchers are homozygous for mating type. Genetics 162:737-745

Loftus BJ, Fung E, Roncaglia P, Rowley D, Amedeo P, Bruno D, Vamathevan J, Miranda M, Anderson IJ, Fraser JA et al (2005) The genome of the basidiomycetous yeast and human pathogen Cryptococcus neoformans. Science 307:1321-1324

Lorenz MC, Fink GR (2001) The glyoxylate cycle is required for fungal virulence. Nature 412:83-86

Lorenz MC, Bender JA, Fink GR (2004) Transcriptional response of Candida albicans upon internalization by macrophages. Eukaryot Cell 3:1076-1087

Lotz H, Sohn K, Brunner H, Muhlschlegel FA, Rupp S (2004) RBR1, a novel pH-regulated cell wall gene of Candida albicans, is repressed by RIM101 and activated by NRG1. Eukaryot Cell 3:776-784

Lyons CN, White TC (2000) Transcriptional analyses of antifungal drug resistance in Candida albicans. Antimicrob Agents Chemother 44:2296-2303

Mateus C, Crow SA Jr, Ahearn DG (2004) Adherence of Candida albicans to silicone induces immediate enhanced tolerance to fluconazole. Antimicrob Agents Chemother 48:3358-3366

Micheli M de, Bille J, Schueller C, Sanglard D (2002) A common drug-responsive element mediates the upregulation 
of the Candida albicans ABC transporters CDR1 and CDR2, two genes involved in antifungal drug resistance. Mol Microbiol 43:1197-1214

Miller MG, Johnson AD (2002) White-opaque switching in Candida albicans is controlled by mating-type locus homeodomain proteins and allows efficient mating. Cell 110:293-302

Morens DM, Folkers GK, Fauci AS (2004) The challenge of emerging and re-emerging infectious diseases. Nature 430:242-249

Mukherjee PK, Chandra J, Kuhn DM, Ghannoum MA (2003) Mechanism of fluconazole resistance in Candida albicans biofilms: phase-specific role of efflux pumps and membrane sterols. Infect Immun 71:4333-4340

Murad AM, d'Enfert C, Gaillardin C, Tournu H, Tekaia F, Talibi D, Marechal D, Marchais V, Cottin J, Brown AJ (2001) Transcript profiling in Candida albicans reveals new cellular functions for the transcriptional repressors CaTup1, CaMig1 and CaNrg1. Mol Microbiol 42:981-993

Murillo LA, Newport G, Lan CY, Habelitz S, Dungan J, Agabian NM (2005) Genome-wide transcription profiling of the early phase of biofilm formation by Candida albicans. Eukaryot Cell 4:1562-1573

Nantel A (2006) The long hard road to a completed Candida albicans genome. Fungal Genet Biol 43:311-315

Nantel A, Dignard D, Bachewich C, Harcus D, Marcil A, Bouin AP, Sensen CW, Hogues H, Hoog M van het, Gordon P et al (2002) Transcription profiling of Candida albicans cells undergoing the yeast-to-hyphal transition. Mol Biol Cell 13:3452-3465

Nett J, Andes D (2006) Candida albicans biofilm development, modeling a host-pathogen interaction. Curr Opin Microbiol 9:340-345

Nicholls S, Straffon M, Enjalbert B, Nantel A, Macaskill S, Whiteway M, Brown AJ (2004) Msn2- and Msn4-like transcription factors play no obvious roles in the stress responses of the fungal pathogen Candida albicans. Eukaryot Cell 3:1111-1123

Nierman WC, Pain A, Anderson MJ, Wortman JR, Kim HS, Arroyo J, Berriman M, Abe K, Archer DB, Bermejo C et al (2005) Genomic sequence of the pathogenic and allergenic filamentous fungus Aspergillus fumigatus. Nature 438:1151-1156

Niewerth M, Kunze D, Seibold M, Schaller M, Korting HC, Hube B (2003) Ciclopirox olamine treatment affects the expression pattern of Candida albicans genes encoding virulence factors, iron metabolism proteins, and drug resistance factors. Antimicrob Agents Chemother 47:1805-1817

Nobile CJ, Mitchell AP (2005) Regulation of cell-surface genes and biofilm formation by the C. albicans transcription factor Bcrlp. Curr Biol 15:1150-1155

Nobile CJ, Mitchell AP (2006) Genetics and genomics of Candida albicans biofilm formation. Cell Microbiol 8:1382-1391

Nobile CJ, Andes DR, Nett JE, Smith FJ, Yue F, Phan QT, Edwards JE, Filler SG, Mitchell AP (2006a) Critical role of Bcr1-dependent adhesins in C. albicans biofilm formation in vitro and in vivo. PLoS Pathog 2:e63

Nobile CJ, Nett JE, Andes DR, Mitchell AP (2006b) Function of Candida albicans adhesin Hwp1 in biofilm formation. Eukaryot Cell 5:1604-1610
O'Rourke SM, Herskowitz I (2004) Unique and redundant roles for HOG MAPK pathway components as revealed by whole-genome expression analysis. Mol Biol Cell 15:532-542

Pfaller MA, Rhine-Chalberg J, Redding SW, Smith J, Farinacci G, Fothergill AW, Rinaldi MG (1994) Variations in fluconazole susceptibility and electrophoretic karyotype among oral isolates of Candida albicans from patients with AIDS and oral candidiasis. J Clin Microbiol 32:59-64

Pompe S, Simon J, Wiedemann PM, Tannert C (2005) Future trends and challenges in pathogenomics. A Foresight study. EMBO Rep 6:600-605

Porta A, Wang Z, Ramon A, Muhlschlegel FA, Fonzi WA (2001) Spontaneous second-site suppressors of the filamentation defect of prr1Delta mutants define a critical domain of Rim101p in Candida albicans. Mol Genet Genomics 266:624-631

Ramon AM, Fonzi WA (2003) Diverged binding specificity of Rim101p, the Candida albicans ortholog of PacC. Eukaryot Cell 2:718-728

Ramon AM, Porta A, Fonzi WA (1999) Effect of environmental $\mathrm{pH}$ on morphological development of Candida albicans is mediated via the PacC-related transcription factor encoded by PRR2. J Bacteriol 181:7524-7530

Redd MJ, Arnaud MB, Johnson AD (1997) A complex composed of tup1 and ssn6 represses transcription in vitro. J Biol Chem 272:11193-11197

Redding S, Smith J, Farinacci G, Rinaldi M, Fothergill A, Rhine-Chalberg J, Pfaller M (1994) Resistance of Candida albicans to fluconazole during treatment of oropharyngeal candidiasis in a patient with AIDS: documentation by in vitro susceptibility testing and DNA subtype analysis. Clin Infect Dis 18:240-242

Richard ML, Nobile CJ, Bruno VM, Mitchell AP (2005) Candida albicans biofilm-defective mutants. Eukaryot Cell 4:1493-1502

Rocha CR, Schroppel K, Harcus D, Marcil A, Dignard D, Taylor BN, Thomas DY, Whiteway M, Leberer E (2001) Signaling through adenylyl cyclase is essential for hyphal growth and virulence in the pathogenic fungus Candida albicans. Mol Biol Cell 12:3631-3643

Rogers PD, Barker KS (2002) Evaluation of differential gene expression in fluconazole-susceptible and -resistant isolates of Candida albicans by cDNA microarray analysis. Antimicrob Agents Chemother 46:3412-3417

Rogers PD, Barker KS (2003) Genome-wide expression profile analysis reveals coordinately regulated genes associated with stepwise acquisition of azole resistance in Candida albicans clinical isolates. Antimicrob Agents Chemother 47:1220-1227

Rubin-Bejerano I, Fraser I, Grisafi P, Fink GR (2003) Phagocytosis by neutrophils induces an amino acid deprivation response in Saccharomyces cerevisiae and Candida albicans. Proc Natl Acad Sci USA 100:1100711012

Sandovsky-Losica H, Chauhan N, Calderone R, Segal E (2006) Gene transcription studies of Candida albicans following infection of HEp2 epithelial cells. Med Mycol 44:329-334

Sarver A, DeRisi J (2005) Fzf1p regulates an inducible response to nitrosative stress in Saccharomyces cerevisiae. Mol Biol Cell 16:4781-4791 
Sigle HC, Thewes S, Niewerth M, Korting HC, Schafer-Korting M, Hube B (2005) Oxygen accessibility and iron levels are critical factors for the antifungal action of ciclopirox against Candida albicans. J Antimicrob Chemother 55:663-673

Silva Ferreira ME da, Malavazi I, Savoldi M, Brakhage AA, Goldman MH, Kim HS, Nierman WC, Goldman GH (2006) Transcriptome analysis of Aspergillus fumigatus exposed to voriconazole. Curr Genet 50:32-44

Slutsky B, Staebell M, Anderson J, Risen L, Pfaller M, Soll DR (1987) "White-opaque transition": a second highfrequency switching system in Candida albicans. J Bacteriol 169:189-197

Smith DA, Nicholls S, Morgan BA, Brown AJ, Quinn J (2004) A conserved stress-activated protein kinase regulates a core stress response in the human pathogen Candida albicans. Mol Biol Cell 15:4179-4190

Sohn K, Senyurek I, Fertey J, Konigsdorfer A, Joffroy C, Hauser N, Zelt G, Brunner H, Rupp S (2006) An in vitro assay to study the transcriptional response during adherence of Candida albicans to different human epithelia. FEMS Yeast Res 6:1085-1093

Sohn K, Urban C, Brunner H, Rupp S (2003) EFG1 is a major regulator of cell wall dynamics in Candida albicans as revealed by DNA microarrays. Mol Microbiol 47:89-102

Sokol-Anderson M, Sligh JE Jr, Elberg S, Brajtburg J, Kobayashi GS, Medoff G (1988) Role of cell defense against oxidative damage in the resistance of Candida albicans to the killing effect of amphotericin B. Antimicrob Agents Chemother 32:702-705

Soll DR (1997) Gene regulation during high-frequency switching in Candida albicans. Microbiology 143:279-288

Sonneborn A, Tebarth B, Ernst JF (1999) Control of whiteopaque phenotypic switching in Candida albicans by the Efg1p morphogenetic regulator. Infect Immun 67:4655-4660

Srikantha T, Borneman AR, Daniels KJ, Pujol C, Wu W, Seringhaus MR, Gerstein M, Yi S, Snyder M, Soll DR (2006) TOS9 regulates white-opaque switching in Candida albicans. Eukaryot Cell 5:1674-1687

Sudbery P, Gow N, Berman J (2004) The distinct morphogenic states of Candida albicans. Trends Microbiol 12:317-324

Tsong AE, Miller MG, Raisner RM, Johnson AD (2003) Evolution of a combinatorial transcriptional circuit: a case study in yeasts. Cell 115:389-399

Ullmann BD, Myers H, Chiranand W, Lazzell AL, Zhao Q, Vega LA, Lopez-Ribot JL, Gardner PR, Gustin MC (2004) Inducible defense mechanism against nitric oxide in Candida albicans. Eukaryot Cell 3:715-723
Urban CF, Reichard U, Brinkmann V, Zychlinsky A (2006) Neutrophil extracellular traps capture and kill Candida albicans yeast and hyphal forms. Cell Microbiol 8:668-676

Venter JC, Adams MD, Myers EW, Li PW, Mural RJ, Sutton GG, Smith HO, Yandell M, Evans CA, Holt RA et al (2001) The sequence of the human genome. Science 291:1304-1351

Vermitsky JP, Earhart KD, Smith WL, Homayouni R, Edlind TD, Rogers PD (2006) Pdr1 regulates multidrug resistance in Candida glabrata: gene disruption and genome-wide expression studies. Mol Microbiol 61:704-722

Vik A, Rine J (2001) Upc2p and Ecm22p, dual regulators of sterol biosynthesis in Saccharomyces cerevisiae. Mol Cell Biol 21:6395-6405

Weissman Z, Kornitzer D (2004) A family of Candida cell surface haem-binding proteins involved in haemin and haemoglobin-iron utilization. Mol Microbiol 53:1209-1220

White TC (1997a) Increased mRNA levels of ERG16, CDR, and MDR1 correlate with increases in azole resistance in Candida albicans isolates from a patient infected with human immunodeficiency virus. Antimicrob Agents Chemother 41:1482-1487

White TC (1997b) The presence of an R467K amino acid substitution and loss of allelic variation correlate with an azole-resistant lanosterol 14alpha demethylase in Candida albicans. Antimicrob Agents Chemother 41:1488-1494

White TC, Marr KA, Bowden RA (1998) Clinical, cellular, and molecular factors that contribute to antifungal drug resistance. Clin Microbiol Rev 11:382-402

Whiteway M, Oberholzer U (2004) Candida morphogenesis and host-pathogen interactions. Curr Opin Microbiol 7:350-357

Wodicka L, Dong H, Mittmann M, Ho MH, Lockhart DJ (1997) Genome-wide expression monitoring in Saccharomyces cerevisiae. Nat Biotechnol 15:1359-1367

Zhang X, De Micheli M, Coleman ST, Sanglard D, MoyeRowley WS (2000) Analysis of the oxidative stress regulation of the Candida albicans transcription factor, Cap1p. Mol Microbiol 36:618-629

Zhao X, Daniels KJ, Oh SH, Green CB, Yeater KM, Soll DR, Hoyer LL (2006) Candida albicans Als3p is required for wild-type biofilm formation on silicone elastomer surfaces. Microbiology 152:2287-2299

Zordan RE, Galgoczy DJ, Johnson AD (2006) Epigenetic properties of white-opaque switching in Candida albicans are based on a self-sustaining transcriptional feedback loop. Proc Natl Acad Sci USA, 103:12807-12812 